Staff Working Paper/Document de travail du personnel 2020-48

Last updated: November 18, 2020

\title{
Short-Run Dynamics in a Search-Theoretic Model of Monetary Exchange
}

by Jonathan $\mathrm{Chiu}^{1}$ and Miguel Molico ${ }^{2}$

\footnotetext{
${ }^{1}$ Funds Management and Banking Department

${ }^{2}$ Financial Stability Department
}

Bank of Canada, Ottawa, Ontario, Canada K1A 0G9

jchiu@bank-banque-canada.ca, mmolico@bank-banque-canada.ca

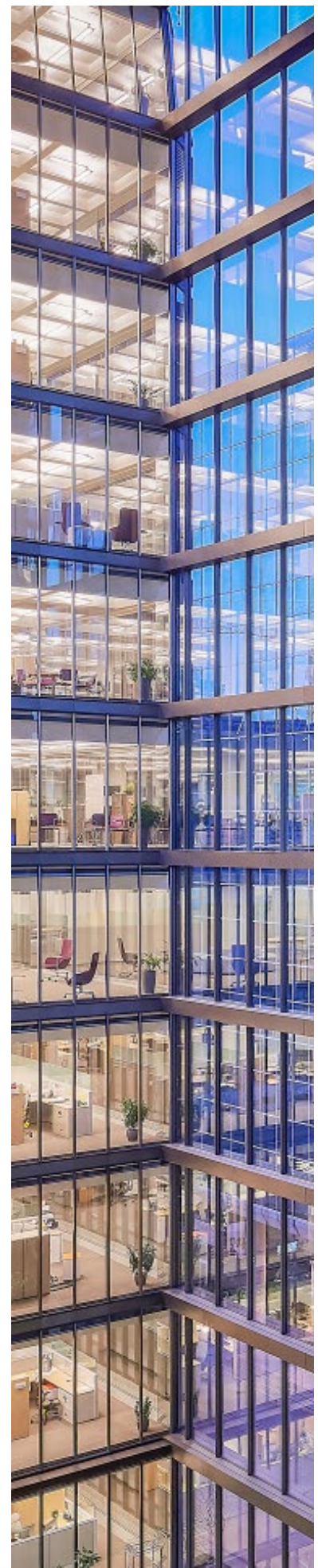

Bank of Canada staff working papers provide a forum for staff to publish work-in-progress research independently from the Bank's Governing Council. This research may support or challenge prevailing policy orthodoxy. Therefore, the views expressed in this paper are solely those of the authors and may differ from official Bank of Canada views. No responsibility for them should be attributed to the Bank. 


\section{Acknowledgements}

We thank two anonymous referees and audiences at the American Economic Association Meeting; the Econometric Society Meeting; the Meeting of the Society for Economic Dynamics; conferences at the federal reserve banks of Chicago, Philadelphia, and St. Louis; the KW25 Conference at the UCSB; and numerous seminars for their helpful comments and suggestions. The views expressed here do not necessarily reflect the views of the Bank of Canada. 


\section{Abstract}

We study the short-run effects of monetary policy in a search-theoretic monetary model in which agents are subject to idiosyncratic liquidity shocks as well as aggregate monetary shocks. Namely, we analyze the role of the endogenous non-degenerate distribution of liquidity, liquidity constraints, and decentralized trade in the transmission and propagation of monetary policy shocks. Money is injected through lump-sum transfers, which have redistributive and persistent effects on output and prices. We propose a new numerical algorithm in the spirit of Algan, Allais and Den Hann. (2008) to solve the model. We find that a one-time expansionary monetary policy shock has persistent positive effects on output, prices, and welfare, even in the absence of nominal rigidities. Furthermore, the effects of positive and negative monetary shocks are typically asymmetric. Negative (contractionary) shocks have bigger effects than positive (expansionary) shocks. In addition, in an economy with larger shocks, the responses tend to be disproportionately larger than those in an economy with smaller shocks. Finally, the effectiveness of monetary shocks depends on the steady-state level of inflation. The higher the average level of inflation (money growth), the bigger the impact effect of a shock of a given size but the smaller its cumulative effect. These results are consistent with existing empirical evidence.

Bank topics: Monetary policy; Transmission of monetary policy; Inflation and prices

JEL codes: E40, E50 


\section{Introduction}

It is a common belief that monetary policy has real and persistent short-run effects. However, the channels through which it operates are still not well understood. Most literature has focused on the role of nominal rigidities in explaining these effects in the context of representative agent models. More recently, some work has focused on the redistributive channel of monetary policy in heterogeneous agents models with uninsurable idiosyncratic risk. In this paper, we study the shortrun effects of monetary policy in a search-theoretic monetary model in which agents are subject to idiosyncratic liquidity shocks as well as aggregate monetary shocks. Namely, we analyze the role of the endogenous non-degenerate distribution of liquidity, liquidity constraints, and decentralized trade in the transmission and propagation of monetary policy shocks.

Starting from the seminal work of Kiyotaki and Wright (1989), a large body of research has been dedicated to developing micro-founded monetary models with decentralized trade to study many theoretical and policy questions. In this class of models, the same frictions that give a role for money will limit the ability of agents to insure against idiosyncratic shocks, typically leading to a non-degenerate distribution of money. ${ }^{1}$ Monetary policy can have long-run and short-run real redistributive effects in these economies. Most of the studies have focused on long-run (steady-state) analysis. For example, Deviatov and Wallace (2001) and Molico (2006) show that redistributive expansionary monetary policy can increase output and welfare. ${ }^{2}$ However, due to technical difficulties, the short-run implications of such models have not been fully explored. The key reason is that the distribution responds endogenously to aggregate shocks and it is technically challenging to keep track of its evolution. The distribution is particularly important in this environment because, unlike in models of centralized trade, agents in a search-theoretic monetary model are subject to random pairwise exchanges, and they need to know not just one market price, but the whole distribution of prices to make their consumption, saving, and portfolio decisions. For this reason, the short-run dynamics of search-theoretic models are still under-examined. Some exceptions, discussed in section

\footnotetext{
${ }^{1}$ Some studies have abstracted from the distributional issues by either assuming that money is an indivisible object (e.g., Wallace 1997) or assuming some form of perfect insurance against the idiosyncratic trading risk (e.g., Shi 1998, Lagos and Wright 2005).

${ }^{2}$ Other studies are investigating the long-run redistributive effects of monetary policy in related environments. For example, Berentsen, Camera and Waller (2005), Chiu and Molico (2010), and Williamson (2006) study non-degenerate distribution in random-matching models. Dressler (2011, 2016) and Boel and Camera (2009) study distributional effects of monetary policy in a model with competitive markets. Menzio, Shi and Sun (2013), Sun and Zhou (2018), Kam and Lee (2018) consider a model with directed search.
} 
6, are Rocheteau, Weill and Wong $(2018,2019)$ and Jin and Zhu (2019).

In this paper, we extend Molico (2006) by incorporating aggregate monetary policy shocks and study the short-run redistributive effects and the internal propagation mechanism of a randommatching model of money. In the model economy, agents are subject to pairwise trading and idiosyncratic uncertainty with regards to their trading opportunities. Heterogeneous idiosyncratic trading histories imply a non-degenerate distribution of money holdings which becomes a state variable summarizing the past histories. Monetary policy, modeled as lump-sum transfers, has redistributive and persistent effects on output and prices - aggregate shocks propagate and diffuse gradually as the money distribution adjusts over time.

As is well known, solving models with heterogeneous agents and aggregate uncertainty constitutes a technical challenge since the set of state variables contains the cross-sectional distribution of agents' characteristics, which is a time-varying infinite-dimensional object in the presence of aggregate uncertainty. We contribute to the literature by developing a numerical algorithm in the spirit of Algan, Allais, and Den Haan (2008) to analyze the short-run distributional effects of monetary policy in random-matching models. In a search-theoretic model of money, the assumption of random bilateral matching implies that the agents must form an expectation regarding the potential gains from trade in order to solve their problems. We follow Algan, Allais, and Den Haan (2008) and parameterize the cross-sectional distribution using a polynomial that matches a set of moments of the distribution. This allows us to compute such expectation using quadrature technique without introducing a significant approximation error. Furthermore, we reduce the number of moments that we keep track of as state variables by introducing the notion of reference moments as in Reiter $(2002) .^{3}$

We solve for the recursive stochastic equilibrium of the model to study the dynamic responses to money growth shocks. In particular, we analyze the impulse response of the distribution of money, output, velocity of money, prices, and welfare to a one-time money growth shock. Furthermore, we study how these responses depend on the direction (positive versus negative) and magnitude (small versus large) of the shocks. Finally, we also study how the effect of money growth shocks depend on the level of trend inflation and the degree of search frictions.

\footnotetext{
${ }^{3}$ These reference moments are fixed to their long-run mean (by simulating the model) and help constrain the shape of the distribution.
} 
We find that a one-time expansionary monetary policy shock has persistent positive effects on output, prices, and welfare, even in the absence of nominal rigidities. Furthermore, the effects of positive and negative monetary shocks are typically asymmetric. Negative (contractionary) shocks have bigger effects on output than positive (expansionary) shocks. In addition, in an economy with larger shocks, the responses tend to be disproportionately larger than those in an economy with smaller shocks. Finally, the effectiveness of monetary shocks depends on the steady-state level of inflation. The higher the average level of inflation (money growth), the bigger the impact effect of a shock of a given size but the smaller its cumulative effect. These results are consistent with existing empirical evidence.

Several explanations have been put forward to explain the empirical evidence on the asymmetric effects of monetary policy (see Morgan (1993)). The two most prominent ones have focused on the role of credit rationing and of downward price rigidities. Our paper highlights an alternative channel. In our model, the real asymmetric effects of monetary policy arise from the interaction between the endogenous non-degenerate distribution of liquidity and the endogenous trading decisions of the agents, in particular, their willingness to spend. Agents face idiosyncratic trading risk, and the accumulation of money balances is the only form of insurance available. As a result, as their liquidity decreases they will be increasingly less willing to spend. By moving poor agents away from their liquidity constraints, a positive money growth shock has an expansionary effect, while a negative shock generates the opposite effect. Agents' response, however, is non-linear. Specifically, an individual responds more strongly to a tightening of the liquidity constraint than to a loosening of it. Furthermore, the strength and the degree of asymmetry of the aggregate response depend on the endogenous fraction of agents with a tight liquidity constraint. This fraction, in turn, depends on the endogenous decision of the agents, influenced by exogenous factors such as the level of trend inflation and the degree of search frictions. Also, the persistence of these effects depends not only on exogenous search frictions, but also on the endogenous spending pattern chosen by the agents. Our results highlight the fact that explicitly modeling the frictions that give rise to money and the exchange process is important not only for the long-run analysis, but also for understanding the short-run effects of monetary policy.

The rest of the paper is organized as follows. Section 2 describes the model environment. Section 3 defines a recursive equilibrium and provides some partial analytical characterization. Section 4 
defines the approximate economy and briefly discusses the numerical algorithm used to compute the recursive equilibria. In section 5, we parameterize, characterize the equilibrium and analyze the effects of monetary policy shocks. Section 6 discusses how our model and findings relate to the literature on the New-Monetarist and the Heterogeneous Agents New-Keynesian (HANK) models. Section 7 concludes the paper.

\section{The Model}

\section{Environment}

In order to study short-run effects of monetary policy in a search model of money, we extend Molico (2006) by introducing monetary growth shocks. Time is discrete. The economy is populated by a $[0,1]$ continuum of infinitely lived agents. These agents specialize in the consumption and production of perfectly divisible nonstorable goods. In particular, specialization is such that no agent consumes the good he or she produces; each agent consumes goods that are produced by a fraction $x$ of the population, and each agent produces goods that are consumed by a fraction $x$ of the population. For simplicity, no two agents consume each other's output. Hence, there is never a double coincidence and hence there is no direct barter. ${ }^{4}$

Agents produce goods by exerting labor effort $h$. The production function is assumed to be linear, given by $q_{t}=h_{t}$. Agents derive utility $u(q)$ from consuming $q$ units of a good and derive disutility $c(h)$ from exerting labor effort $h$. Assume $u$ is $C^{2}$, strictly increasing, strictly concave, and satisfies $u(0)=0$. Also, $c$ is $C^{2}$, strictly increasing, strictly convex, and satisfies $c(0)=0$. Let $0<\beta<1$ denote the discount factor.

The economy uses fiat money, which is a perfectly divisible and costlessly storable object that cannot be produced or consumed by any private individual. Agents can hold any non-negative amount of money $\hat{m} \in \mathbb{R}_{+}$. The money stock at the beginning of period $t$ is denoted as $M_{t}$. In what follows we express all nominal variables as fractions of the beginning of the period money supply (before any of the current period's money transfers, which we will describe below), i.e., $m_{t} \equiv \hat{m}_{t} / M_{t}$. Let $\lambda_{t}: \mathfrak{B}_{\mathbb{R}_{+}} \rightarrow[0,1]$ denote the probability measure associated with the distribution

\footnotetext{
${ }^{4}$ For money to be valued, it is only required that in some meetings there is no double coincident of wants. For simplicity, we focus on purely monetary trades and, by assumption, preclude the possibility of barter.
} 


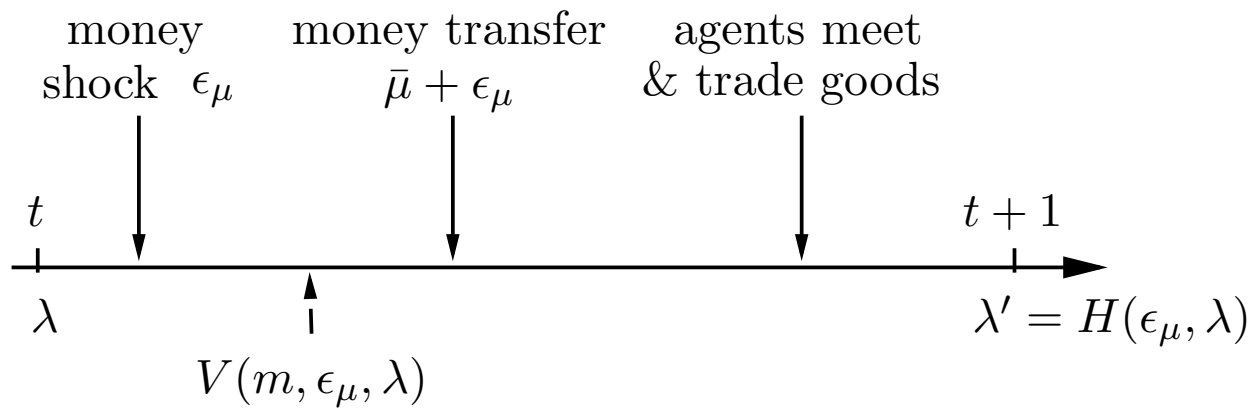

Figure 1: Time-line

of money holdings (as a fraction of the beginning of period money supply) at the beginning of period $t$, where $\mathfrak{B}_{\mathbb{R}_{+}}$denotes the Borel subsets of $\mathbb{R}_{+}$. The money supply grows at rate $\mu_{t}=$ $\bar{\mu}+\varepsilon_{\mu t}, M_{t+1}=\mu_{t} M_{t}$, where $\varepsilon_{\mu t}$ is an i.i.d. money growth shock. Let $\varepsilon_{\mu t} \in\{-\Delta, 0, \Delta\}$ with $\operatorname{Pr}\left(\varepsilon_{\mu}=-\Delta\right)=\operatorname{Pr}\left(\varepsilon_{\mu}=\Delta\right)=\tau<\frac{1}{2}$. Newly printed money is injected via lump-sum transfers to all agents (Figure 1).

\section{Meetings}

Each period, agents are randomly bilaterally matched. Given the pattern of specialization, in a given meeting, an individual will be a potential buyer with probability $x$. Also, with probability $x$ the agent will be a potential seller. By assumption, there are never double-coincidence-of-wants meetings. When individuals meet in a single coincidence meeting, they bargain over the amount of money and goods to be traded. Let $q\left(m_{b}, m_{s} ; \varepsilon_{\mu t}, \lambda_{t}\right) \geq 0$ denote the amount of good and $d\left(m_{b}, m_{s} ; \varepsilon_{\mu t}, \lambda_{t}\right) \geq 0$ the amount of money to be determined by the bargaining process at date $t$ between a buyer with money holdings $m_{b}$ and a seller with $m_{s}$, when the current state of the economy is described by $\left(\varepsilon_{\mu t}, \lambda_{t}\right)$. We assume that when the two agents meet, the buyer makes a take-it-or-leave-it offer to the seller, extracting all of the seller's expected surplus. This concludes the description of the environment. In what follows, we will gradually build towards the definition of an equilibrium.

\section{Recursive Equilibrium}

In this section we define a recursive equilibrium for this economy. A key element in such definition is the law of motion of the aggregate state of the economy. The aggregate state is given by $\left(\varepsilon_{\mu}, \lambda\right)$ : 
that is, the current monetary shocks and the current probability measure over money holdings. The part of the law of motion that concerns $\varepsilon_{\mu}$ is exogenous, and is described by the i.i.d. process governing $\varepsilon_{\mu}$. The part that concerns updating $\lambda$ is denoted as $H, \lambda^{\prime}=H\left(\varepsilon_{\mu}, \lambda\right)$, where prime denotes a variable in the following period. When making decisions, an individual agent cares about the aggregate state, $\left(\varepsilon_{\mu}, \lambda\right)$, as well as the individual state, which is their own money holdings $m$. Agents take as given the law of motion of the distribution of money holdings, the process governing the monetary policy shocks, and the monetary policy rule.

Let $V$ denote the value of money at the beginning of the period before monetary transfers but after observing the current period's aggregate shock $\varepsilon_{\mu}$. The following equation describes the value function of an agent with money holding $m$ given the aggregate state $\left(\varepsilon_{\mu}, \lambda\right) .^{5}$

$$
\begin{aligned}
V\left(m ; \varepsilon_{\mu}, \lambda\right)= & x \beta \int_{0}^{\infty} u\left[q\left(m, m_{s} ; \varepsilon_{\mu}, \lambda\right)\right]+E_{\varepsilon_{\mu}^{\prime}}\left\{V\left[\frac{m+\mu-1-d\left(m, m_{s} ; \varepsilon_{\mu}, \lambda\right)}{\mu} ; \varepsilon_{\mu}^{\prime}, \lambda^{\prime}\right]\right\} \lambda\left(m_{s}\right) d m_{s} \\
& \left.+x \beta \int_{0}^{\infty}-c\left(q\left(m_{b}, m ; \varepsilon_{\mu}, \lambda\right)\right)\right]+E_{\varepsilon_{\mu}^{\prime}}\left\{V\left[\frac{m+\mu-1+d\left(m_{b}, m ; \varepsilon_{\mu}, \lambda\right)}{\mu} ; \varepsilon_{\mu}^{\prime}, \lambda^{\prime}\right]\right\} \lambda\left(m_{b}\right) d m_{b} \\
& +(1-2 x) \beta E_{\varepsilon_{\mu}^{\prime}} V\left[\frac{m+\mu-1}{\mu} ; \varepsilon_{\mu}^{\prime}, \lambda^{\prime}\right]
\end{aligned}
$$

where $\mu=\bar{\mu}+\varepsilon_{\mu}$. Also, $E$ denotes the expectations operator and a prime superscript denotes a next period's variable.

The first line of the RHS describes the situation where an agent is a buyer, which happens with probability $x$. When a buyer meets a seller with money holding $m_{s}$, the buyer will consume $q\left(m, m_{s} ; \varepsilon_{\mu}, \lambda\right)$ and reduce their money holding by $d\left(m, m_{s} ; \varepsilon_{\mu}, \lambda\right)$. Since the monetary distribution is non-degenerate, an agent draws a random trading partner from the distribution with density $\lambda(m)$. The second line captures the situation where this agent is a seller, which happens with probability $x$. The third line describes the case of a non-trader, which happens with probability $1-2 x$. In any case, the agent receives a money transfer at a rate $\mu-1$, and the real balance in next period is re-normalized by the money growth rate $\mu$. Since buyers make take-it-or-leave-it offers to sellers, only buyers can receive a positive trade-surplus. Therefore, the value function can be

\footnotetext{
${ }^{5}$ We assume that $V(m)$ is continuous, which is sufficient for $q\left(m_{b}, m_{s}\right)$ and $d\left(m_{b}, m_{s}\right)$ to be measurable functions and therefore the integral to be well defined.
} 
simplified to

$$
\begin{aligned}
V\left(m ; \varepsilon_{\mu}, \lambda\right)= & x \beta \int_{0}^{\infty}\left\{u\left[q\left(m, m_{s} ; \varepsilon_{\mu}, \lambda\right)\right]+\right. \\
& E_{\varepsilon_{\mu}^{\prime}}\left\{V\left[\frac{m+\mu-1-d\left(m, m_{s} ; \varepsilon_{\mu}, \lambda\right)}{\mu} ; \varepsilon_{\mu}^{\prime}, \lambda^{\prime}\right]-V\left[\frac{m+\mu-1}{\mu} ; \varepsilon_{\mu}^{\prime}, \lambda^{\prime}\right]\right\} \lambda\left(m_{s}\right) d m_{s} \\
& +\beta E_{\varepsilon_{\mu}^{\prime}} V\left[\frac{m+\mu-1}{\mu} ; \varepsilon_{\mu}^{\prime}, \lambda^{\prime}\right]
\end{aligned}
$$

The terms of trade $d\left(m_{b}, m_{s} ; \varepsilon_{\mu}, \lambda\right)$ and $q\left(m_{b}, m_{s} ; \varepsilon_{\mu}, \lambda\right)$ solve $^{6}$ :

$$
\max _{0 \leq d \leq m_{b}+\mu-1, q \geq 0} u(q)+E_{\varepsilon_{\mu}^{\prime}} V\left[\frac{m_{b}+\mu-1-d}{\mu}, \varepsilon_{\mu}^{\prime}, \lambda^{\prime}\right]
$$

subject to

$$
\begin{aligned}
c(q) & =E_{\varepsilon_{\mu}^{\prime}}\left\{V\left[\frac{m_{s}+\mu-1+d}{\mu}, \varepsilon_{\mu}^{\prime}, \lambda^{\prime}\right]-V\left[\frac{m_{s}+\mu-1}{\mu} ; \varepsilon_{\mu}^{\prime}, \lambda^{\prime}\right]\right\}, \\
\lambda^{\prime} & =H\left(\varepsilon_{\mu}, \lambda\right) \\
\mu & =\bar{\mu}+\varepsilon_{\mu} .
\end{aligned}
$$

Here, a buyer chooses the terms-of-trade $(q, d)$ to maximize the buyer's payoff subject to liquidity constraint $m_{b}+\mu-1 \geq d$ and the participation constraint of the seller (3). The buyer takes as given the law of motion of the distribution (4) and the policy rule (5).

We now describe the law of motion of the distribution of money holdings $H$. The law of motion of the money holdings distribution can be described as a Markov process with an associated transition function $\Pi\left(m, B ; \varepsilon_{\mu}, \lambda\right)$. Intuitively, $\Pi\left(m, B ; \varepsilon_{\mu}, \lambda\right)$ is the probability that an individual currently with money holdings $m$ will have money holdings in $B \in \mathfrak{B}_{\mathbb{R}_{+}}$next period, given the current aggregate state $\left(\varepsilon_{\mu}, \lambda\right)$. In what follows we will construct such function.

Let $T=\{$ buyer, seller, neither $\}$ and define the space $(T, \mathfrak{T})$, where $\mathfrak{T}$ is the $\sigma$-algebra. Define the probability measure $\tau: \mathfrak{T} \rightarrow[0,1]$, with $\tau($ buyer $)=\tau($ seller $)=x$, and $\tau($ neither $)=1-2 x$. Then, $(T, \mathfrak{T}, \tau)$ is a measure space. Define an event to be a pair $e=(t, m)$, where $t \in T, m \in \mathbb{R}_{+}$.

\footnotetext{
${ }^{6}$ Given the assumed continuity of $V$, it can easily be shown by the Theorem of the Maximum that the set of solutions of the maximization problem is non-empty, compact-valued, and upper hemicontinuous (Theorem 3.6 in Stokey, Lucas and Prescott, 1989). Thus, by the Measurable Selection Theorem, it admits a measurable selection (Theorem 7.6 in Stokey, Lucas and Prescott, 1989). We define $d\left(m_{b}, m_{s} ; \varepsilon_{\mu}, \lambda\right)$ and $q\left(m_{b}, m_{s} ; \varepsilon_{\mu}, \lambda\right)$ to be that selection.
} 
Intuitively, $t$ denotes an agent's trading status and $m$ the money holdings of his current trading partner. Let $(E, \mathfrak{E})$ be the space of such events, where $E=T \times \mathbb{R}_{+}$and $\mathfrak{E}=\mathfrak{T} \times \mathfrak{B}_{\mathbb{R}_{+}}$. Furthermore, let $\xi: \mathfrak{E} \rightarrow[0,1]$ be the product probability measure induced by $\tau$ and $\lambda$. Define the mapping $\theta(m, e): \mathbb{R}_{+} \times E \rightarrow \mathbb{R}_{+}$, where

$$
\theta\left(m, e ; \varepsilon_{\mu}, \lambda\right)= \begin{cases}\frac{m+\mu-1-d\left(m, m_{s} ; \varepsilon_{\mu}, \lambda\right)}{\mu}, & \text { if } e=\left(\text { buyer }, m_{s}\right) \\ \frac{m+\mu-1+d\left(m_{b}, m ; \varepsilon_{\mu}, \lambda\right)}{\mu}, & \text { if } e=\left(\text { seller }, m_{b}\right) \\ \frac{m+\mu-1}{\mu}, & \text { otherwise }\end{cases}
$$

We can now define $\Pi: \mathbb{R}_{+} \times \mathfrak{B}_{\mathbb{R}_{+}} \rightarrow[0,1]$ to be

$$
\Pi\left(m, B ; \varepsilon_{\mu}, \lambda\right) \equiv \xi\left(\left\{e \in E \mid \theta\left(m, e ; \varepsilon_{\mu}, \lambda\right) \in B\right\}\right) .
$$

$\Pi$ is a well-defined transition function. ${ }^{7}$ Then,

$$
\lambda^{\prime}(B)=H\left(\varepsilon_{\mu}, \lambda\right)(B) \equiv \int_{0}^{\infty} \Pi\left(m, B ; \varepsilon_{\mu}, \lambda\right) \lambda(d m) \forall B \in \mathfrak{B}_{\mathbb{R}_{+}}
$$

A recursive equilibrium is then a law of motion $H$, a value function $V$, terms of trade $d$ and $q$, and monetary policy such that (i) $V$ satisfies (1), (ii) $d$ and $q$ solve the bargaining problem (2), and (iii) $H$ is defined by (6).

\section{Partial Analytical Characterization}

As is the case for most heterogeneous agent macroeconomic models, we are unable to generally prove the existence or uniqueness of an equilibrium and to provide a full analytical characterization of its properties. In the following sections we will develop a numerical algorithm that will allow us to solve for and numerically characterize the equilibrium of an approximate economy. In this section, we provide some partial analytical characterization of the equilibrium, assuming that one exists and that the value function $V$ is twice continuously differentiable, strictly increasing and strictly concave in $m$. These assumed properties always appear to hold in our numerical exercises. The following result establishes some properties of the solution to the bargaining problem.

\footnotetext{
${ }^{7}$ By construction, for each $m, \Pi\left(m, B ; \varepsilon_{\mu}, \lambda\right)$ is a probability measure on $\left(\mathbb{R}_{+}, \mathfrak{B}_{\mathbb{R}_{+}}\right)$. Furthermore, given the measurability of $d\left(m, m_{s} ; \varepsilon_{\mu}, \lambda\right), \Pi\left(m, B ; \varepsilon_{\mu}, \lambda\right)$ is a $\mathfrak{B}_{\mathbb{R}_{+}}$-measurable function.
} 
Result 1 Let $V$ be a twice continuously differentiable, strictly increasing and strictly concave function of $m$. The terms of trade $q\left(m_{b}, m_{s}\right)$ and $d\left(m_{b}, m_{s}\right)$ that solve the bargaining problem (2)-(5) satisfy:

(i) $q$ is increasing in $m_{b}$ and decreasing in $m_{s}$;

(ii) $d$ is increasing in $m_{b}$, with $\frac{\partial d}{\partial m_{b}} \leq 1$, and non-monotonic in $m_{s}$;

(iii) $q$ is concave in $m_{b}$ as long as $\frac{\partial^{2} d}{\partial m_{b}^{2}}$ is not too large. In particular, this is true when the money constraint binds, that is, $d\left(m_{b}, m_{s}\right)=m_{b}+\mu-1$, in which case $\frac{\partial^{2} d}{\partial m_{b}^{2}}=0$.

The intuition for these results is straightforward. The richer the buyer, the lower the buyer's marginal valuation of money and thus the higher the amount of money the buyer will be willing to spend for a given amount of goods. Given a fixed wealth of the seller, the larger the amount of money the seller will receive, the higher the amount of goods the seller will be willing to produce. Thus $d$ and $q$ are increasing in $m_{b}$. If the additional amount of money the buyer is willing to give as the buyer's money holdings increase is non-increasing (or at least does not increase too much), the seller's production will increase at a diminishing rate given the diminishing valuation of money and increasing costs of production. The fact that $q$ is decreasing in $m_{s}$ follows directly from the decreasing valuation of money and strict convexity of the cost function. Proof of Result 1 is provided in Appendix A. While we are able to establish the monotonicity of the terms of trade, we are not able, in general, to establish their concavity or convexity.

By defining the per-unit price at a meeting, $p\left(m_{b}, m_{s}\right) \equiv \frac{d\left(m_{b}, m_{s}\right)}{q\left(m_{b}, m_{s}\right)}$, we can further establish that $p$ is increasing in $m_{b}$ and concave in $m_{b}$ as long as the purchasing power of money does not decline too quickly. The intuition is the following. As the buyer's money holdings go up, the buyer wants to spend some on current consumption. But as the seller's marginal cost is driven up and the seller's marginal value of money is driven down, the purchasing power of an additional dollar drops, leading to a higher price. If the purchasing power of money does not decline too quickly ( $c^{\prime \prime}$ and $V^{\prime \prime}$ small), then the marginal effect on price is diminishing as a result of the diminishing marginal increase in consumption.

Finally, by defining the efficient quantity, $q^{*}$, as the quantity that maximizes pairwise welfare, 
i.e., satisfies $u^{\prime}\left(q^{*}\right)=c^{\prime}\left(q^{*}\right)$, one can easily show that if $m_{b}<m_{s}, q<q^{*}$. ${ }^{8}$ That is, if the buyer is poorer than the seller, the quantity traded is inefficiently low. Furthermore, if the budget constraint of the buyer does not bind, $q>q^{*}$ if and only if $m_{b}-d>m_{s}+d$, that is, if the buyer's money holdings after trade are higher than the seller's. And, $q=q^{*}$ if and only if $m_{b}-d=m_{s}+d$.

\section{The Approximate Economy}

Solving the stochastic heterogeneous agents model of the previous section with a continuum of agents constitutes an impossible technical problem given that the state vector includes the whole distribution of money, which is an infinite-dimensional object. Recently, algorithms have been proposed that summarize the cross-section distribution of agents' characteristics by a small number of moments (therefore making the dimension of the state space tractable) and calculate the law of motion for these state variables using simulation procedures. The best-known examples of this approach are those of Den Hann (1997), Rios-Rull (1997) and Krusell and Smith (1998).

An added difficulty of computing equilibria in our model is that it requires us to compute the expected gain of being a buyer - the integral in equation (1) - which requires us to integrate over the money holdings of the sellers. To compute that expectation with precision might require us to keep track of a large number of moments. To overcome this difficulty we follow Algan, Allais and Den Haan (2008) to parameterize the cross-sectional distribution and use reference moments as in Reiter (2002). Parameterizing the cross-sectional distribution allows us to obtain a numerical solution using standard quadrature and projection techniques. Using reference moments allows us to get a better characterization of the cross-sectional distribution without increasing the number of state variables. Although we provide a detailed description of our algorithm in Appendix B, we direct the reader to Algan, Allais and Den Haan for further advantages of their method.

As mentioned above, we follow Algan, Allais, and Den Hann (2008) and parameterize the crosssectional distribution by a polynomial $P(m ; \rho)$ of order $\bar{N}$ with coefficients $\rho=\left[\rho_{0}, \rho_{1}, \ldots, \rho_{\bar{N}}\right]$ to

${ }^{8}$ Note that if there is trade, the F.O.C.s of the bargaining problem imply

$$
\frac{u^{\prime}(q)}{c^{\prime}(q)}=\frac{\mu \phi+V^{\prime}\left(\frac{m_{b}+\mu-1-d}{\mu}\right)}{V^{\prime}\left(\frac{m_{s}+\mu-1+d}{\mu}\right)},
$$

where $V^{\prime}(\cdot) \equiv E_{\varepsilon_{\mu}^{\prime}} \frac{\partial V\left(\cdot, \varepsilon_{\mu}^{\prime}, \lambda^{\prime}\right)}{\partial m}$ and $\phi$ is the Lagrangian multiplier associated with the liquidity constraint of the buyer. 
match not only the moments $s=\left[s_{1}, \ldots, s_{N}\right]$ used as state variables but also a set of extended moments $\tilde{s}=\left[s_{N+1}, \ldots, s_{\bar{N}}\right] .{ }^{9}$ We describe in detail the procedure to obtain the extended moments in Appendix B but, in brief, these are the higher order average moments implied by the decision rules of the agents and obtained by simulating the model. These reference moments discipline/constrain the shape of the distribution. By adopting a particular class of approximating polynomials, one can reduce this problem to a convex optimization problem. ${ }^{10}$ In particular, the polynomial of order $\bar{N}$ is written as:

$$
P(m, \rho)=\rho_{0} \exp \left\{\rho_{1}\left[m-s_{1}\right]+\rho_{2}\left[\left(m-s_{1}\right)^{2}-s_{2}\right]+\ldots+\rho_{\bar{N}}\left[\left(m-s_{1}\right)^{\bar{N}}-s_{\bar{N}}\right]\right\} .
$$

When the density is constructed in this particular way, the coefficients, except for $\rho_{0}$, can be found with the following minimization routine:

$$
\min _{\rho_{1}, \rho_{2}, \ldots, \rho_{\bar{N}}} \int_{0}^{\infty} P(m, \rho) d m
$$

The parameter $\rho_{0}$ can be determined by the condition that the density integrates to $1, \int_{0}^{\infty} P(m, \rho) d m=$ 1.

Finally, since we only use a limited set of moments as state variables, $s=\left[s_{1}, \ldots, s_{N}\right]$, the transition law only needs to specify how this limited set of moments evolves over time. Thus, instead of computing $H$, we now calculate $s^{\prime}=\Gamma_{n}\left(\varepsilon_{\mu}, s ; \gamma_{n}\right)$, where $\Gamma_{n}$ is an $n^{t h}$-order polynomial with coefficients $\gamma_{n}$.

The approximate problem can then be written as:

$$
\begin{aligned}
V\left(m ; \varepsilon_{\mu}, s\right)= & x \beta \int_{0}^{\infty}\left\{u\left[q\left(m, m_{s} ; \varepsilon_{\mu}, s\right)\right]+\right. \\
& E_{\varepsilon_{\mu}^{\prime}}\left\{V\left[\frac{m+\mu-1-d\left(m, m_{s} ; \varepsilon_{\mu}, s\right)}{\mu} ; \varepsilon_{\mu}^{\prime}, s^{\prime}\right]\right. \\
& \left.-V\left[\frac{m+\mu-1}{\mu} ; \varepsilon_{\mu}^{\prime}, s^{\prime}\right]\right\} P\left(m_{s} ; \rho\right) d m_{s}+\beta E_{\varepsilon_{\mu}^{\prime}} V\left[\frac{m+\mu-1}{\mu} ; \varepsilon_{\mu}^{\prime}, s^{\prime}\right],
\end{aligned}
$$

\footnotetext{
${ }^{9}$ At the request of our referees, we have compared this parametric method to approximate the distribution with a non-parametric method based on Molico (2006). We find that, for our model and parametrization, the approximations obtained using these two methods are qualitatively and quantitatively very similar. We report these results in an online Appendix.

${ }^{10}$ Without the convexity of the problem, obtaining convergence can be problematic without finding a good initial condition.
} 
where $d\left(m_{b}, m_{s} ; \varepsilon_{\mu}, s\right)$ and $q\left(m_{b}, m_{s} ; \varepsilon_{\mu}, s\right)$ solve:

$$
\max _{0 \leq d \leq m_{b}+\mu-1, q \geq 0} u(q)+E_{\varepsilon_{\mu}^{\prime}} V\left[\frac{m_{b}+\mu-1-d}{\mu}, \varepsilon_{\mu}^{\prime}, s^{\prime}\right]
$$

subject to

$$
\begin{aligned}
c(q) & =E_{\varepsilon_{\mu}^{\prime}}\left\{V\left[\frac{m_{s}+\mu-1+d}{\mu}, \varepsilon_{\mu}^{\prime}, s^{\prime}\right]-V\left[\frac{m_{s}+\mu-1}{\mu} ; \varepsilon_{\mu}^{\prime}, s^{\prime}\right]\right\} \\
s^{\prime} & =\Gamma_{n}\left(\varepsilon_{\mu}, s ; \gamma_{n}\right) \\
\mu & =\bar{\mu}+\varepsilon_{\mu} .
\end{aligned}
$$

In the benchmark implementation of the algorithm, we only keep track of the second moment $s=s_{2}$ as a state variable, that is, we set $N=2$, but use three additional reference moments (moments 3 to 5). ${ }^{11}$ We later verify the robustness of our results to the increase in the number of moments used as a state variable. Note that in this model, the first moment is constant at $s_{1}=1$, since the average money holdings as a fraction of the total money stock is 1 . For each $\varepsilon_{\mu}$ we approximate the value function on a grid of money holdings, $m$, and second moments, $s_{2}$. In the $m$ direction, we use an uneven grid and a shape-preserving interpolation routine. This is done to guarantee that the algorithm preserves the concavity of $V$ with respect to $m$. In the $s_{2}$ direction, we use an evenly spaced grid and piecewise-linear interpolation.

\section{$5 \quad$ Numerical Analysis}

In what follows, we use the numerical algorithm discussed above, and described in detail in Appendix $\mathrm{B}$, to find and characterize equilibria of the model and study the short-run dynamics of this economy. In particular, we characterize the stochastic steady-state equilibrium of the model and illustrate the effects of aggregate monetary policy shocks on output, the distribution of prices and the aggregate price level, the velocity of money, and the distribution of consumption and welfare by computing impulse responses to one-time monetary policy shocks. We analyze how these responses depend on the average rate of inflation as well as the direction and the magnitude of the monetary shocks. This allows us to study whether positive (expansionary) or negative (contractionary) monetary policy

\footnotetext{
${ }^{11}$ Note that the polynomial used to parametrize the distribution matches all the five moments.
} 
shocks have symmetric effects, whether the impact of shocks is linear in size, and whether the trend inflation affects the effectiveness of monetary policy.

\section{Parameterization}

For illustration purposes and ease of comparison with previous work, we adopt as a benchmark the functional forms and parametrization from Molico (2006). The utility and cost functions are given by:

$$
\begin{aligned}
& u(q)=A * \ln (1+q), \\
& c(q)=\frac{1}{\bar{q}-q}-\frac{1}{\bar{q}},
\end{aligned}
$$

with $A=100$ and $\bar{q}=1$. We set the probability of being a buyer/seller to $x=0.25$ and $\beta=0.99$, that is, a period is a quarter. The monetary authority targets a constant annual money growth rate of $2 \%$, i.e. $\bar{\mu}=0.005$. The i.i.d. monetary shocks, $\varepsilon_{\mu}$, are drawn from the set $\{-0.0025,0,0.0025\}$ with $\operatorname{Pr}\left(\varepsilon_{\mu}=-0.0025\right)=\operatorname{Pr}\left(\varepsilon_{\mu}=0.0025\right)=\tau=0.49$, that is, the shocks to money growth are $+/-1 \%$ annualized. Due to the lack of centralized trades, it is not feasible to calibrate the current model to match the level of the velocity of money. However, the money holdings dispersion and price dispersion implied by the model are still empirically reasonable. ${ }^{12}$

To solve the model, we use the second moment as a state variable and the third to fifth moments as reference moments. Below, we will show that this provides a good approximation of the equilibrium. In particular, adding additional moments as state variables does not meaningfully change the equilibrium.

\section{Benchmark Equilibrium}

We find that the law of motion of the endogenous aggregate state is well approximated by a linear function. For our benchmark parametrization,

$$
\left.s_{2}^{\prime}=0.002461-0.334 * \varepsilon_{\mu}+0.987 * s_{2}, \quad \text { (with } R^{2}=0.999984\right) .
$$

\footnotetext{
${ }^{12}$ For example, the 80 th percentile of money holding is 1.34 times the average money holding in the model. According to the balances of transaction accounts in the 2013 Survey of Consumer Finance, the corresponding number is 1.23 in the data (Rocheteau, Weill and Wong (2018)). In the model, the coefficient of variation of prices is $25 \%$. According to Kaplan and Menzio (2015), the corresponding number across all goods is $19 \%-36 \%$.
} 
Here, $s_{2}$ denotes the second moment of the distribution of money holdings in the current period, and $s_{2}^{\prime}$ denotes the second moment in the next period. Note that a positive monetary shock decreases the dispersion of money holdings (i.e., $\frac{\mathrm{d} s_{2}^{\prime}}{\mathrm{d} \varepsilon_{\mu}}=-0.334$ ), and the distributional effects of monetary shocks are very persistent (the parameter associated with $s_{2}$ is close to one). The idea is that, due to market incompleteness, the equilibrium distribution of monetary holding is non-degenerate, as it will be shown later. As a result, a lump sum transfer of money will have distributional effects, redistributing real money balances from those with above-average liquidity to those with below-average liquidity. This effect tends to reduce the dispersion of money holdings, and thus the coefficient attached to $\varepsilon_{\mu}$ in the equation above is negative. This feature is very different from the Lagos-Wright type of model in which the distribution of money holding is degenerated and thus monetary shocks have no persistent real effects through the distributional channel.

In the absence of additional monetary shocks, the distribution will gradually converge to the stochastic steady state. ${ }^{13}$ In this model economy, the only way of insuring oneself against idiosyncratic shocks is to carry large precautionary money balances, generating a low velocity of money circulation, which accounts for the slow dynamics of the distribution and thus a very high persistence. Furthermore, given the unwillingness of agents to spend, the fraction of agents that will be liquidity-constrained in equilibrium is low, leading to quantitatively small (but very persistent) redistributive effects. This is a well-known feature of this simple model. As a result, in our analysis we focus on the qualitative features of the model as opposed to its quantitative implications. For versions of the model that match the velocity of money, we expect the degree of persistence to be much smaller and the quantitative effects of monetary shocks to be much larger. ${ }^{14}$

Figure 2 illustrates the equilibrium value function for different $m$ and $s_{2}$ when $\varepsilon_{\mu}=0$. One can see clearly that there is diminishing marginal value of money. Also, the value of money is slightly increasing in the variance in an almost linear fashion. The value functions for other values of $\varepsilon_{\mu}$ look similar and thus are omitted. In general, we find that a positive (negative) monetary shock

\footnotetext{
${ }^{13}$ We follow, Coeurdacier, Rey and Winant. (2011) in defining the stochastic steady-state equilibrium (or risky steady state) as the point where agents choose to stay at a given date if they expect future risk and if the realization of the shocks is zero at this date. We compute the stochastic steady state by simulating the economy with $\varepsilon_{\mu}=0$ until it converges.

${ }^{14}$ Chiu and Molico $(2010,2011)$ suggest an extension of this model, where agents can access another (centralized) market in which they can imperfectly insure against idiosyncratic risk and re-balance their portfolio. This extended model can quantitatively match the data while preserving the interesting distributional effects of monetary policy analyzed in this paper. Our numerical algorithm could, in principle, be applied to these models and is left to future work.
} 

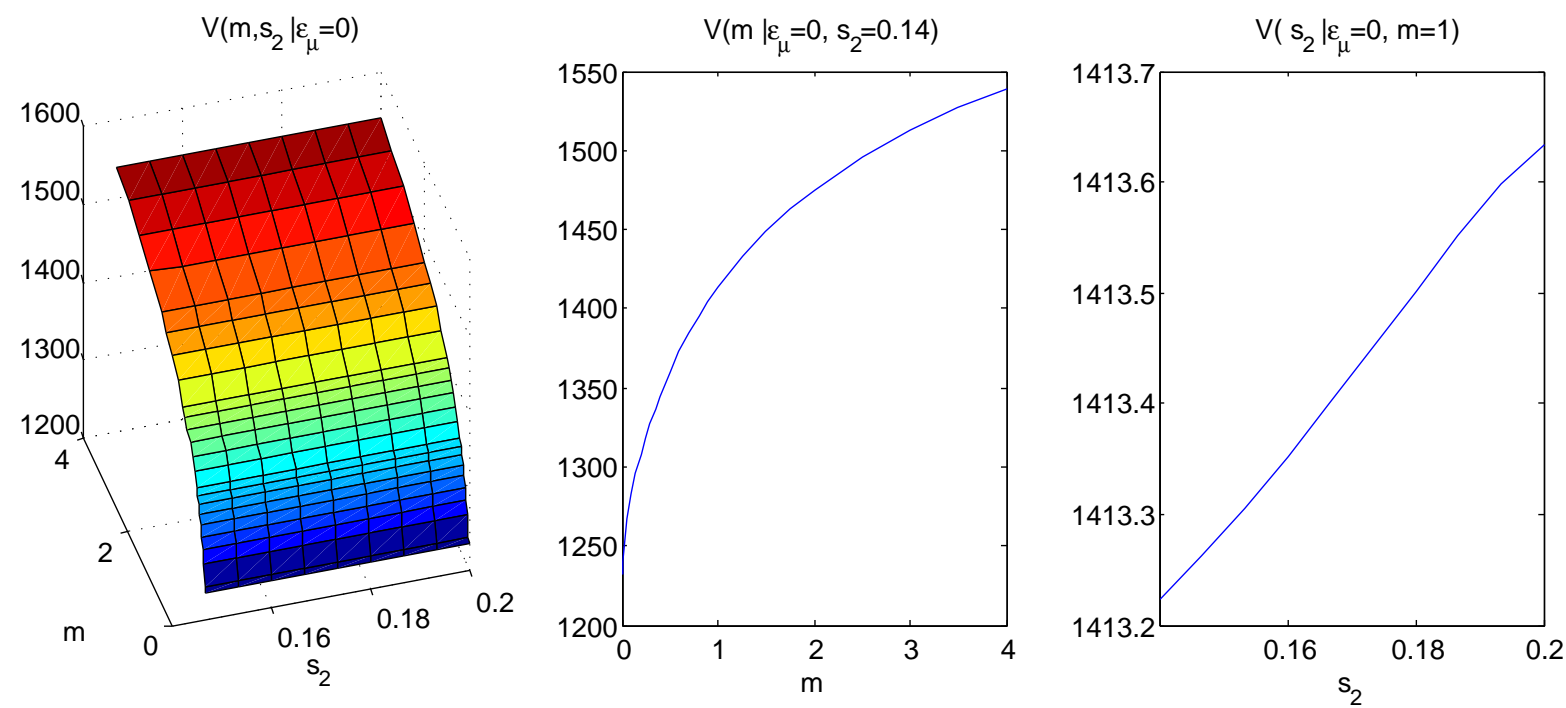

Figure 2: Value function.

leads to a decrease (increase) in the marginal value of money. After a positive (negative) shock, the value function of money holdings tilt down (up), with an increase (decrease) of the value of money for money balances close to zero and a decrease (increase) of the value for high money balances.

\section{Stochastic Steady state}

We begin by characterizing the stochastic steady-state equilibrium of the benchmark economy, as this will help us better understand its dynamic properties. Figures 3 and 4 describe the terms of trade in a match as functions of the money holdings of the buyer and the seller in a match. We report (i) the quantities of goods traded (normalized by the efficient quantity, $q^{*}$ ), (ii) the money balances traded, (iii) the fraction of money holding spent by the buyer (propensity to spend), and (iv) the per unit price $p\left(m_{b}, m_{s}\right)=\frac{d\left(m_{b}, m_{s}\right)}{q\left(m_{b}, m_{s}\right)}$ for $q\left(m_{b}, m_{s}\right)>0$. As in Molico (2006), $q$ is increasing and concave in $m_{b}$ and decreasing and convex in $m_{s}$. The intuition is as follows. As shown before, as buyers get richer, they want to spend more on current consumption, i.e., $\frac{\partial d}{\partial m_{b}}>0$. But as the seller's marginal cost is driven up and the seller's marginal value of money is driven down, the quantity the buyer is able to purchase will increase at a slower rate as long as $\frac{\partial^{2} d}{\partial m_{b}^{2}} \leq 0$ (or it is small enough), which, as seen in panel 3, holds for the benchmark economy. Note also that poorer buyers typically consume less than the efficient quantity while richer buyers typically consume more than the efficient quantity. As the seller becomes richer, the marginal dollar spent by the buyer becomes 

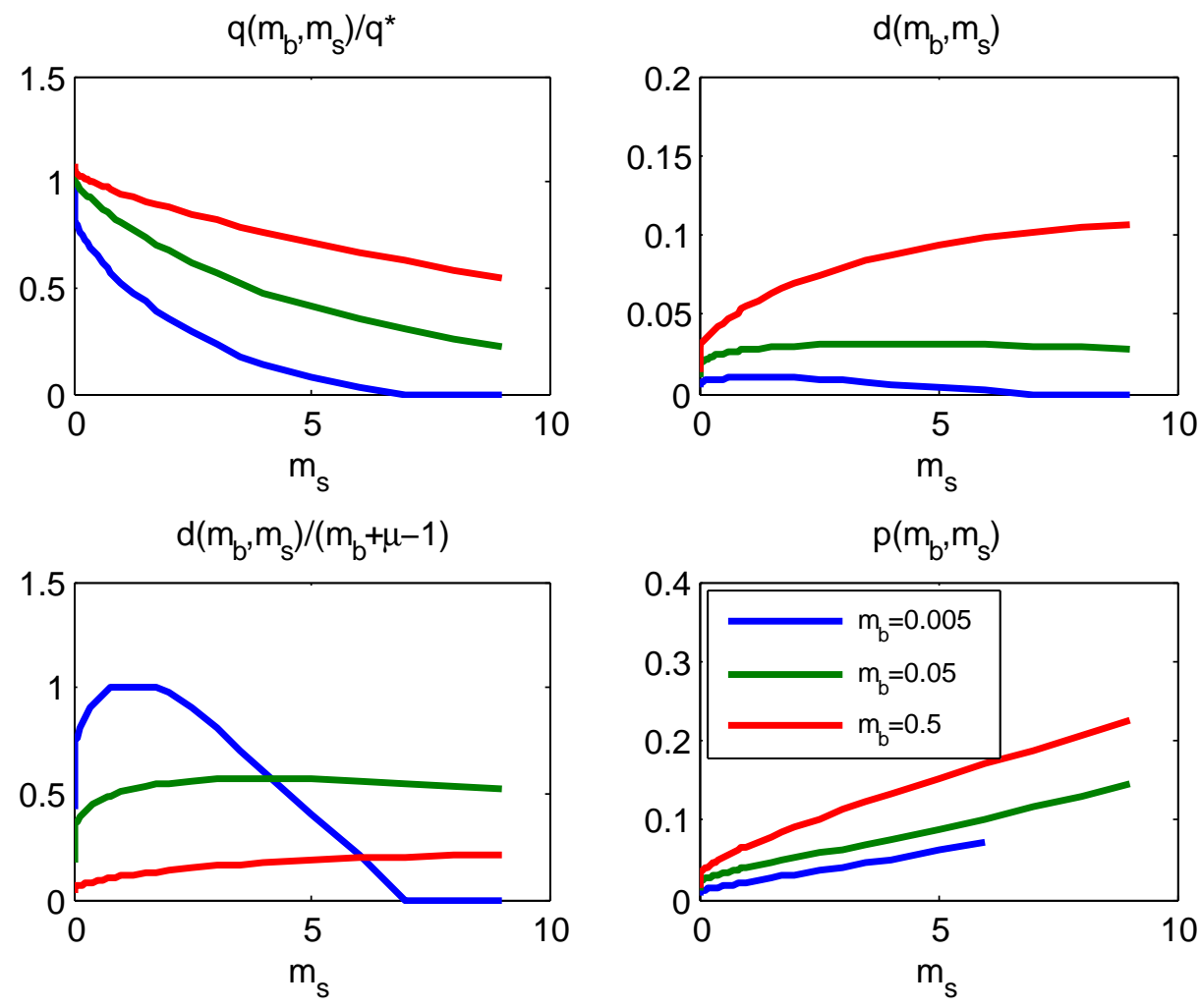

Figure 3: Stochastic steady state: Terms of trade and $m_{s}$.

less valuable. As the buyer needs to pay more to buy the same quantity, production drops. In the benchmark economy, consumption is also convex in the seller's money holdings, especially for poor buyers. Again, note that very poor sellers typically produce more than the efficient quantity while richer sellers will typically produce less than the efficient quantity. Given these properties, ceteris paribus, a decrease in the dispersion of money holdings will lead to an increase in the quantity of goods traded in the economy if the concavity of $q$ as a function of $m_{b}$ dominates the convexity of $q$ as a function of $m_{s}$, as is the case for our parametrization, and generally to an increase in welfare. ${ }^{15}$

The second panel of Figures 3 and 4 shows that the amount of money that gets exchanged between a buyer and a seller is increasing in $m_{b}$, as shown before, and, for our benchmark economy, concave in $m_{b}$. However, $d$ is generally non-monotonic and concave in $m_{s}$, as argued before. Namely, for poor buyers, $d$ is initially an increasing function of $m_{s}$, until the buyer's liquidity constraint is

\footnotetext{
${ }^{15}$ In a similar setting, Jin and Zhu (2019) also find that consumption is concave in the buyer's money holdings and convex in the seller's money holdings. However, for their parametrization, the convexity in $m_{s}$ dominates the concavity in $m_{b}$. As a result, a one-time monetary injection that increases (decreases) the dispersion of money holdings increases (decreases) output and reduces (increases) welfare. This is due to the fact that in their economy, agents over produce.
} 

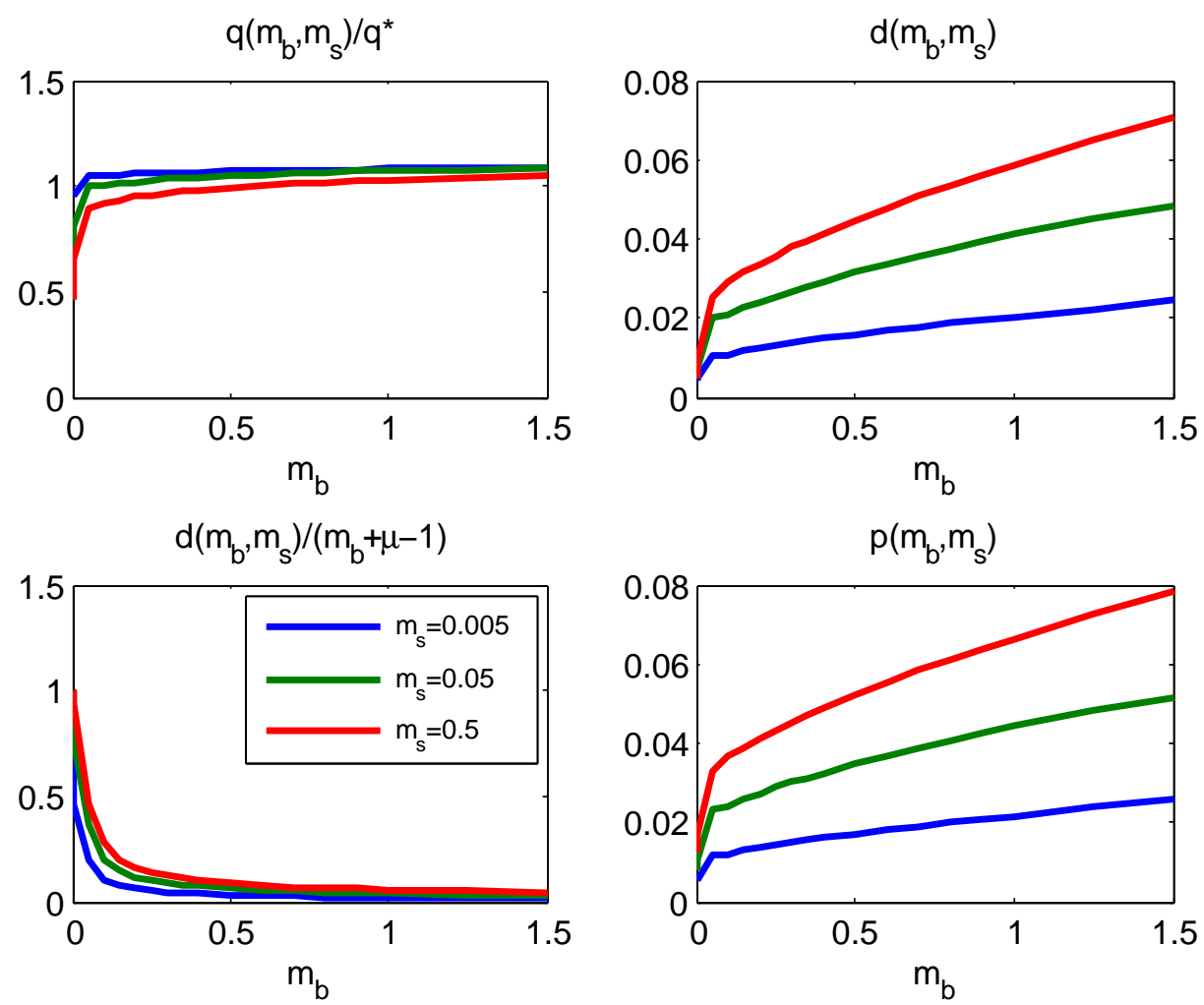

Figure 4: Stochastic steady state: Terms of trade and $m_{b}$.
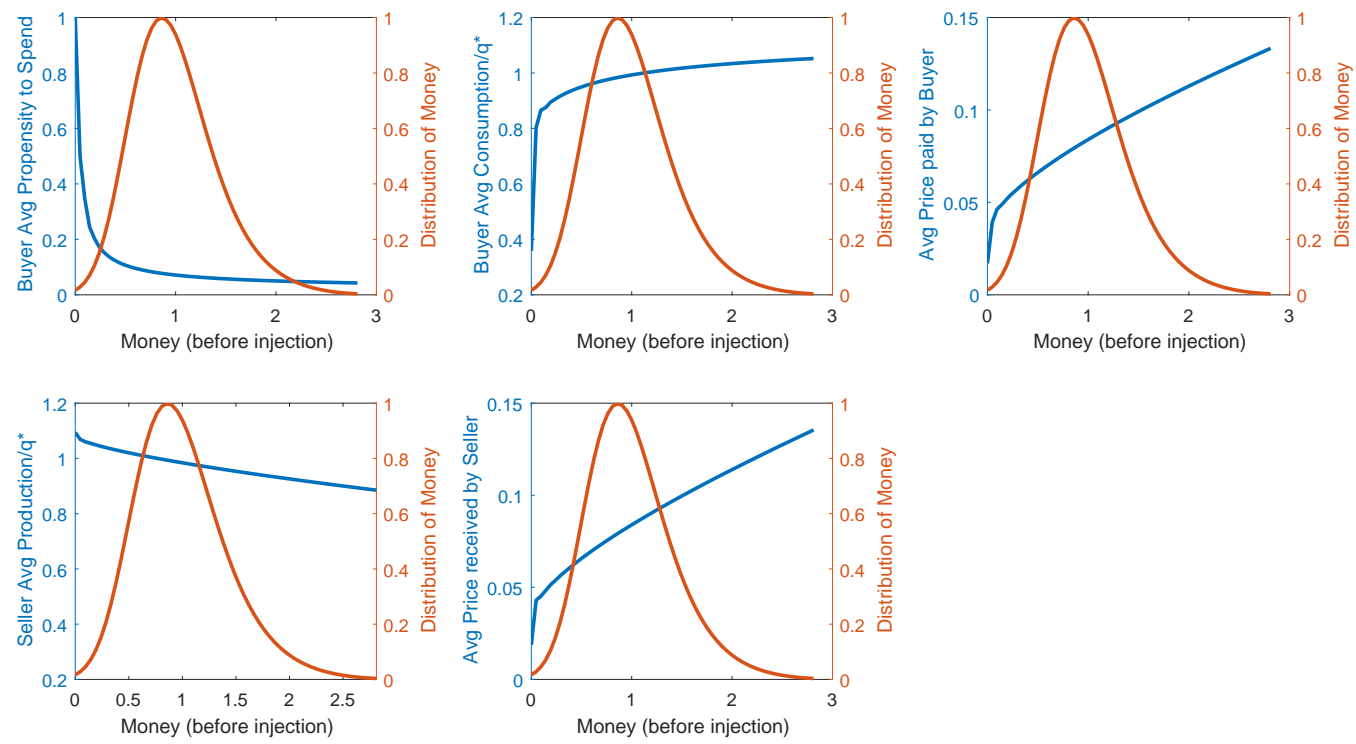

Figure 5: Stochastic steady state. 
binding, at which point it becomes constant. For the same poor buyer, at higher values of $m_{s}, d$ becomes decreasing in $m_{s}$. This can be more easily seen in the third panel, which plots the fraction of a buyer's money holding that is spent at a meeting (propensity to spend). Note that in equilibrium poor enough buyers will be liquidity- constrained and spend all their money in some meetings (as indicated by the flat top part of the blue curve), implying in equilibrium a positive mass of agents holding zero money balances until the next money injection. Furthermore, the fraction of money buyers will spend at a meeting is decreasing in their money holdings. Given the concavity of $d$ with respect to $m_{b}$ and $m_{s}$, ceteris paribus, a decrease in the dispersion of money implies an increase in the velocity of money, $x \iint d\left(m_{b}, m_{s}\right) P\left(m_{b}\right) P\left(m_{s}\right) d m_{b} d m_{s} \cdot{ }^{16}$

Finally, the fourth panel plots the per-unit price at a meeting. As can be seen, $p$ is increasing and concave in both $m_{b}$ and $m_{s}$. The intuition is straightforward: the richer the buyer or the seller, the lower their marginal value of money and thus, for the same amount of goods, the buyer will be willing to give up more money (pay a higher price) and the seller will demand more money (and thus a higher price). Thus, ceteris paribus, a decrease in the dispersion of money implies an increase in the average price per meeting, $\iint p\left(m_{b}, m_{s}\right) P\left(m_{b}\right) P\left(m_{s}\right) d m_{b} d m_{s}$.

Figure 5 plots the stochastic steady-state distribution of money (at the beginning of the period before the monetary injection) against several aggregate functions of interest. As expected, the distribution of money balances is non-degenerate. Note that, for our benchmark parametrization, the density at zero is small but positive (as indicated by the positive y-intercept of the red density curve in the figure), implying that there is a small mass of agents that will have no money at the beginning of the period before the monetary injection. As we just saw, they have spent all their money as buyers in the previous period. The first panel also plots a buyer's average propensity to spend, that is, the fraction of the buyer's money balances (including the monetary transfer) that the buyer will spend on average (across all potential meetings with sellers with different money balances), $\int \frac{d\left(m, m_{s}\right)}{m+\mu-1} P\left(m_{s}\right) d m_{s}$. Consistent with what we saw for the individual meeting terms of trade, the average propensity to spend is close to one for poor buyers and decreasing in the buyer's money balances. The second panel plots the buyer's average/expected consumption as a function of the buyer's money holdings normalized by the efficient quantity, $\int \frac{q\left(m, m_{s}\right)}{q^{*}} P\left(m_{s}\right) d m_{s}$. Again,

\footnotetext{
${ }^{16}$ Note that, given our normalization, $d\left(m_{b}, m_{s}\right)$ is the nominal value of output traded at a meeting as a fraction of the money supply, $M$.
} 
consistent with the pattern of trade, the buyer's average/expected consumption is increasing and concave in $m_{b}$. Note also that, poor buyers on average consume inefficiently low quantities of goods while very rich individuals consume inefficiently high quantities of goods. Also, the average/expected price paid by the buyer is an increasing and concave function of $m_{b}$. The fourth panel plots the seller's average/expected production normalized by the efficient quantity. Again, consistent with the equilibrium terms of trade, the average/expected production is decreasing and convex in the sellers' money holdings. Poor sellers on average produce inefficiently high quantities of output, while very rich sellers produce inefficiently high quantities of goods. Finally, the fifth panel shows that the average/expected price paid by the seller is also an increasing and concave function of the seller's money holdings. Interestingly, on average, buyers and sellers with the same wealth trade at very similar prices. Furthermore, the wealthier the individual, the higher the price at which they will on average transact as a buyer or a seller.

\section{Impulse Responses: One-time Positive Money Growth Shock}

We now turn to the analysis of the dynamic properties of the economy. Figure 6 illustrates the impulse responses to a positive shock to money growth for the benchmark economy starting at the stochastic steady-state equilibrium. As explained above, the shock generates a negative persistent effect on the dispersion of money holding due to a redistribution of liquidity from agents with above-average money holdings to agents with below-average money holdings. The decrease in the dispersion of money holdings leads to an increase in aggregate output (as long as the concavity of $q$ with respect to $m_{b}$ is stronger than the convexity of $q$ with respect to $m_{s}$, which is true for the benchmark economy). The effect is mostly driven by the relaxation of the liquidity constraint of poorer buyers (or the move away from the liquidity constraint) and the increase in the production of rich sellers as they become relatively poorer, as can be seen in Table 1. Thus, the more mass in the tails of the distribution - in particular, the more agents are constrained (or close to being constrained) in equilibrium - the larger the redistributive effect. The effect is persistent because the distribution adjusts gradually over time. The lengthy transition is due partly to trading frictions (i.e.. bilateral exchange with random matching) that slow down monetary exchange and partly to 
agents' incentives to spend slowly over time for self-insurance motives. ${ }^{17}$

Table 1: Distributional Effects of Positive Money Shock on Impact

\begin{tabular}{l|r|r|r|r|r|r|r}
\hline Percentile & $1 \%$ & $10 \%$ & $25 \%$ & $50 \%$ & $75 \%$ & $90 \%$ & $99 \%$ \\
\hline$m$ & 0.194 & 0.491 & 0.694 & 1.000 & 1.252 & 1.574 & 2.232 \\
\hline$\% \Delta$ in consumption & 0.04205 & 0.01429 & 0.00543 & -0.00115 & -0.00402 & -0.00604 & -0.00805 \\
$\% \Delta$ in production & -0.01729 & -0.00551 & -0.00025 & 0.00610 & 0.01038 & 0.01517 & 0.02368 \\
\hline
\end{tabular}

The welfare, measured by average utility in the economy, also exhibits a similar positive and persistent response. Recall from Figures 3 and 5 that poor agents consume inefficiently low quantities of goods and produce inefficiently high quantities, while rich agents consume inefficiently high quantities of goods and produce inefficiently low quantities. Thus, a decrease in the dispersion of money leads to an unequivocal increase in welfare. As $d$ is a function concave in $m_{b}$ and $m_{s}$, a decrease in the dispersion of money implies a higher average spending. Hence, the velocity of circulation of money tends to rise. Finally, the average price per meeting (as a fraction of $M$ ) also increases given that, as was seen in Figures 3 and 5, $p$ is concave in the money of the buyer and the seller. In the long run, the percentage increase in price is equal to the percentage increase in the money supply.

\section{The Asymmetric Effects of Positive and Negative Shocks}

We now compare the responses to positive and negative monetary shocks. Figure 7 compares the impulse responses of the benchmark economy to a positive and negative one-time money growth shock. Table 2 reports the impact and cumulative effects of each shock. As can be seen, the economy responds more strongly to a negative monetary growth shock than to a positive shock of the same magnitude. The asymmetric effect of positive and negative shocks is due to the fact that agents respond more strongly to a tightening of their liquidity constraint (or a move towards the constraint) as a result of a negative shock than to a loosening (or a move away from the constraint) as a result of a positive shock. This is reflected in the non-linear responses of consumption, production, amounts

\footnotetext{
${ }^{17}$ Note that, in the benchmark economy, a fraction of the population spend all their money, implying a mass of agents in the distribution holding zero money balances. Given this, a monetary shock can lead to a discrete jump in aggregate output on impact, with the magnitude of the jump depending on the fraction of agents constrained and how strongly they react. Also, the impulse responses have a "spike" on the impact period because the monetary injection lasts for only one period. The impulse response functions become smooth when the shocks are permanent.
} 

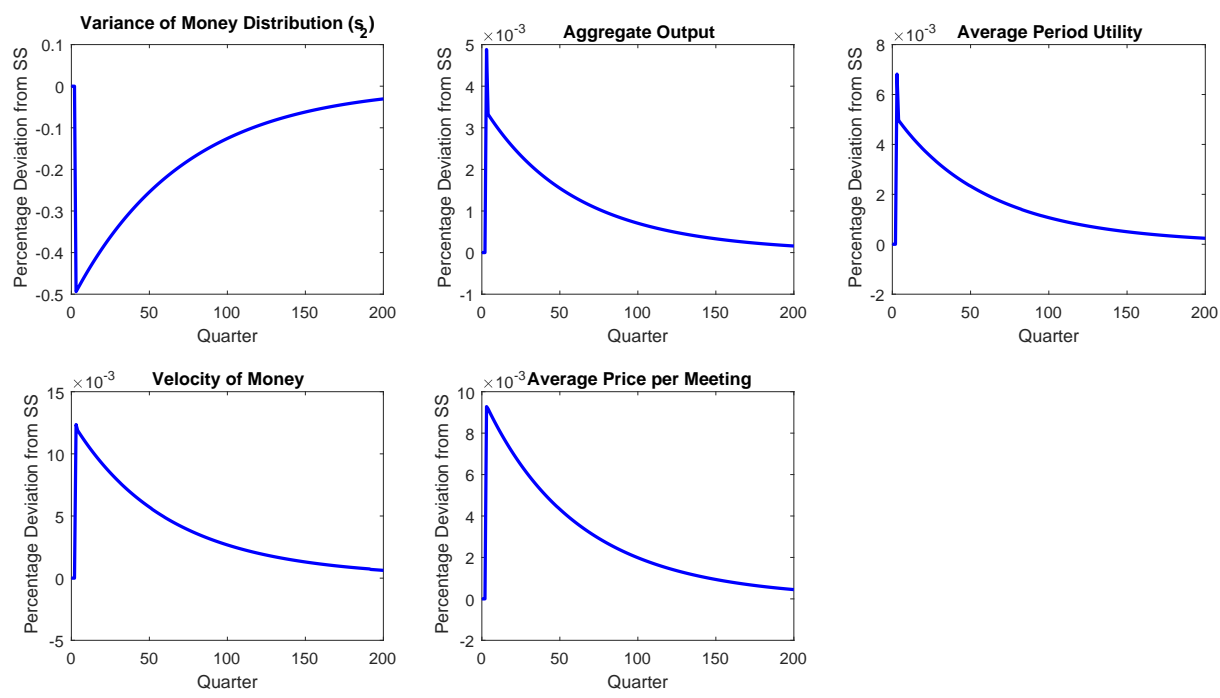

Figure 6: Impulse response: One-time positive money growth shock (benchmark economy)

of money traded and prices plotted in Figure 5 and discussed above. Our results are consistent with empirical findings regarding the effects of expansionary and contractionary monetary policy on output. ${ }^{18}$ Note also that the asymmetry does not rely on any degree of downward price rigidity, credit rationing, or loss of confidence by consumers and firms as emphasized by others. ${ }^{19}$

Table 2: Effect of Unanticipated Money Growth Shock (benchmark economy)

\begin{tabular}{l|r|r|r|r}
\hline & \multicolumn{2}{|c|}{ Negative shock } & \multicolumn{2}{c}{ Positive shock } \\
\hline Variable & On impact & Cumulative & On impact & Cumulative \\
\hline$\% \Delta$ in output & -0.00551 & -0.20540 & 0.00488 & 0.20355 \\
$\% \Delta$ in avg price & -0.01334 & -0.57859 & 0.00928 & 0.56394 \\
\hline
\end{tabular}

\footnotetext{
${ }^{18}$ A significant body of empirical literature has discussed the asymmetric effects of monetary shocks on output. While the evidence is not always conclusive and the results sometimes depend on the particular periods considered or the indicators of monetary policy stance (e.g., changes in monetary aggregates, policy rates or narrative indexes), there is strong evidence of the asymmetric effect of positive and negative monetary policy shocks on output: in particular, that negative shocks have stronger effects than positive ones. See DeLong and Summers (1988), Cover(1992), Morgan (1993), Rhee and Rich (1995), Ravn and Sola (1996), Karras (1996), Karras and Stockes (1999a, 1999b), Weise (1999), and Ülke and Berument (2016).

${ }^{19}$ Three main reasons have been advanced for the asymmetry. Many authors have argued that monetary policy will have asymmetric effects on real output if prices are less flexible downward than upward. Others have argued that credit constraints arise if tight policy makes banks less willing to lend to some borrowers (credit rationing). Finally, some authors have argued that the loss of confidence by firms and consumers during recessions makes expansionary monetary policy less effective. For further discussion of the reasons for asymmetry see Morgan (1993).
} 

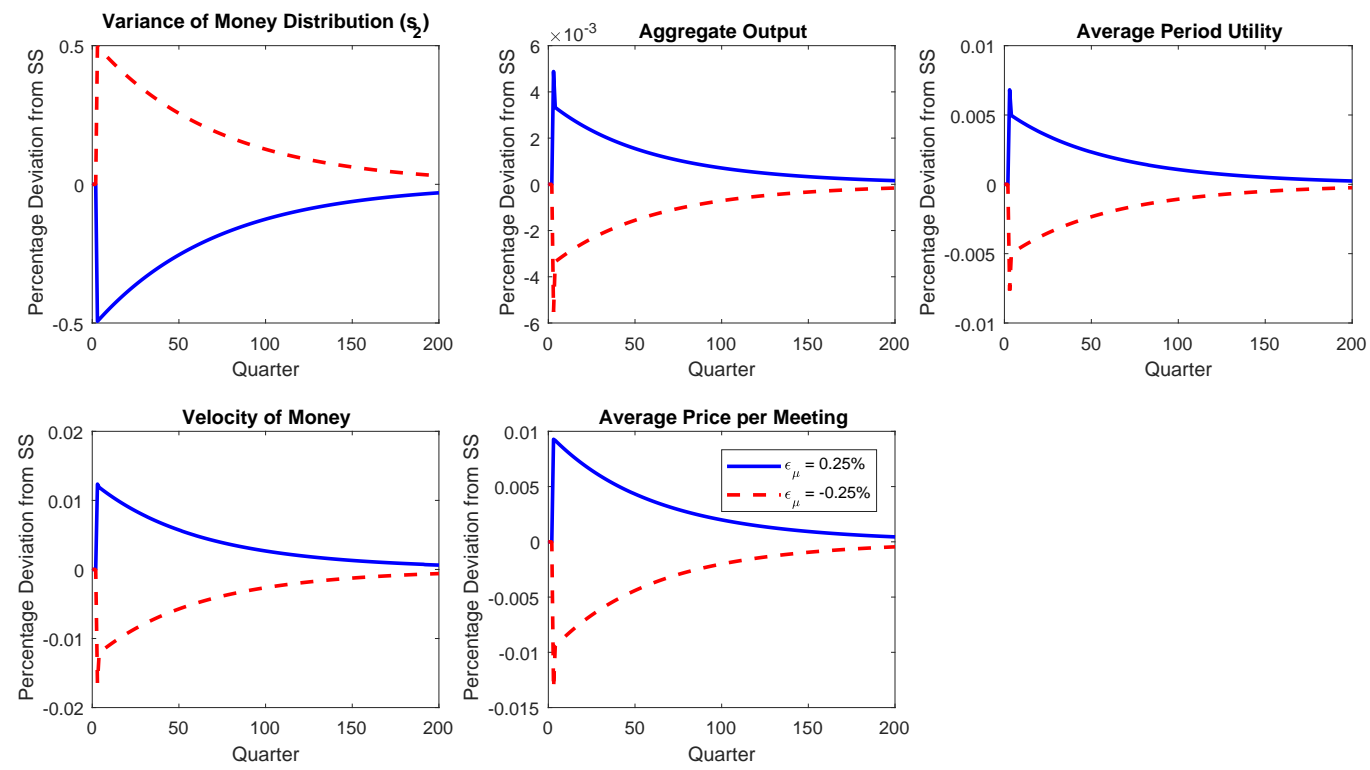

Figure 7: Impulse response to positive and negative shocks (benchmark economy)

\section{Economy with Large Shocks versus Economy with Small Shocks}

Here we compare our benchmark economy to an identical economy where the money growth shocks are twice as large. Namely, in the second economy, the i.i.d. monetary shocks, $\varepsilon_{\mu}$, are drawn from the set $\{-0.005,0,0.005\}$ with the same probability $\operatorname{Pr}\left(\varepsilon_{\mu}=-0.005\right)=\operatorname{Pr}\left(\varepsilon_{\mu}=0.005\right)=\tau=0.49$, that is, the shocks to money growth are $+/-2 \%$ annualized. Note that this is different from studying the effects of shocks of different sizes in one single economy. ${ }^{20}$ Figure 8 plots the impulse responses of the two economies to a positive money growth shock. Table 3 reports the impact and cumulative effects of small and large, positive and negative shocks. As can be seen, in the economy with larger shocks monetary policy is more effective: the effect is more than proportional to the change in size of the shock. Hence, there is a second type of asymmetry, one between small and large shocks. Furthermore, the asymmetry between positive and negative shocks is larger in the economy with larger shocks. The intuition for these results lies once again in how the shocks affect the fraction of agents at or near their liquidity constraint and the non-linear responses of agents.

\footnotetext{
${ }^{20} \mathrm{~A}$ cleaner exercise would be to consider an economy subject to both small and large shocks and compare the impulse responses to both shocks. However, that would increase the state space and, due to its computational cost, is not pursued here.
} 

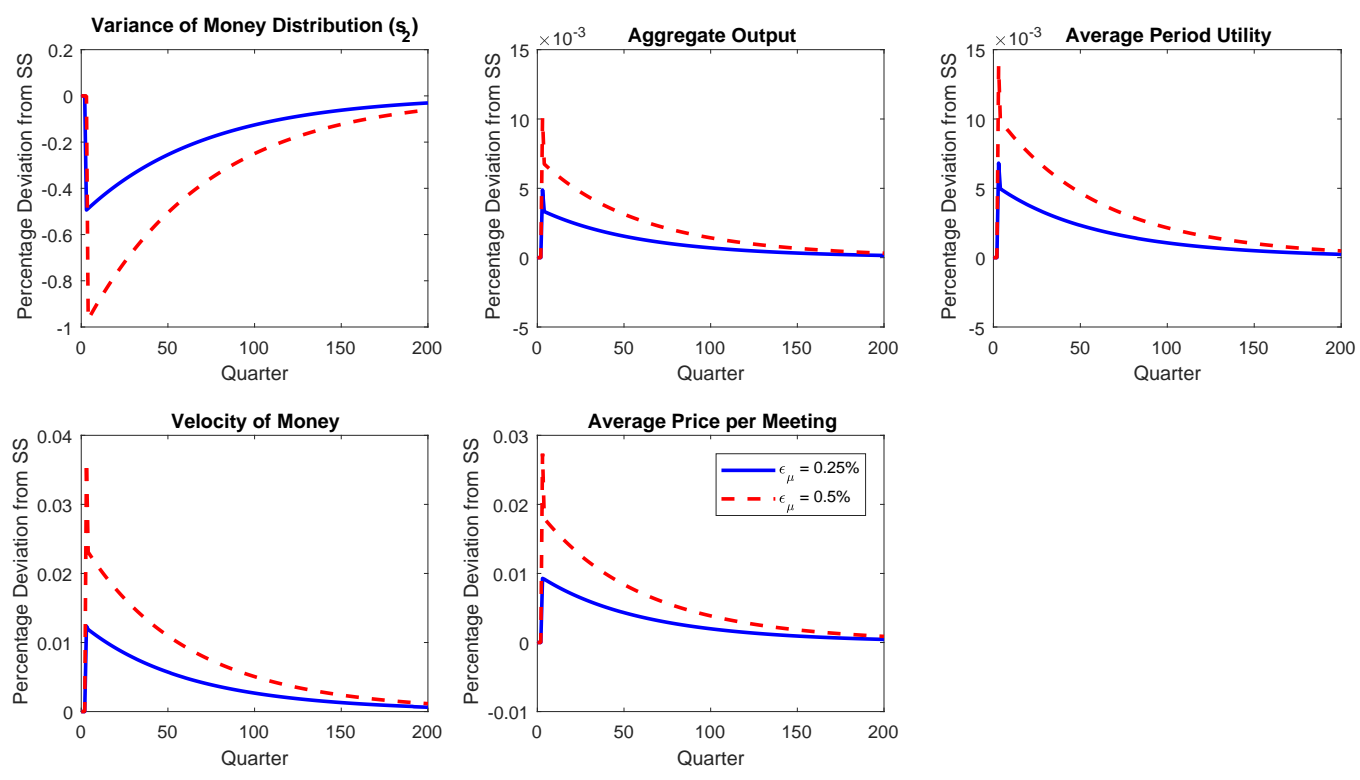

Figure 8: The effect of small versus large shocks

Table 3: Economies with Small versus Large Money Growth Shocks

\begin{tabular}{l|r|r|r|r|r|r}
\hline & \multicolumn{2}{|c|}{ Small shock economy } & \multicolumn{2}{c|}{ Large shock economy } & \multicolumn{2}{c}{ Ratio } \\
\hline & \multicolumn{2}{|c|}{$(|\varepsilon \mu|=0.25 \%)$} & \multicolumn{2}{c}{$(|\varepsilon \mu|=0.5 \%)$} & \\
\hline Variable & On impact & Cumulative & On impact & Cumulative & On impact & Cumulative \\
\hline \% in output & & & & & & \\
Positive shock & 0.00488 & 0.20355 & 0.01005 & 0.41289 & 2.05943 & 2.02845 \\
Negative shock & -0.00551 & -0.20540 & -0.01266 & -0.42155 & 2.29764 & 2.05234 \\
\hline$\% \Delta$ in avg price & & & & & & \\
Positive shock & 0.00928 & 0.56394 & 0.02917 & 1.10954 & 3.14332 & 1.96748 \\
Negative shock & -0.01334 & -0.57859 & -0.02453 & -1.11412 & 1.83883 & 1.92558 \\
\hline
\end{tabular}

\section{The Role of Search Frictions}

We now consider two economies that differ solely in their degree of search frictions ${ }^{21}, x-$ our benchmark economy and an economy with less search friction, $x=0.499$ (or alternatively, with more patient agents). Figure 9 plots the impulse responses to a positive shock to money growth $\left(\varepsilon_{\mu}=0.0025\right)$ for both economies.

Interestingly, although the degree of search frictions decreases, the persistence of the dispersion of the money distribution is unaffected. While, this result might seem at first counter-intuitive, it can

\footnotetext{
${ }^{21}$ Or, alternatively, differ in the discount factor, as what matters in the economy is the effective arrival rate $x \beta$.
} 

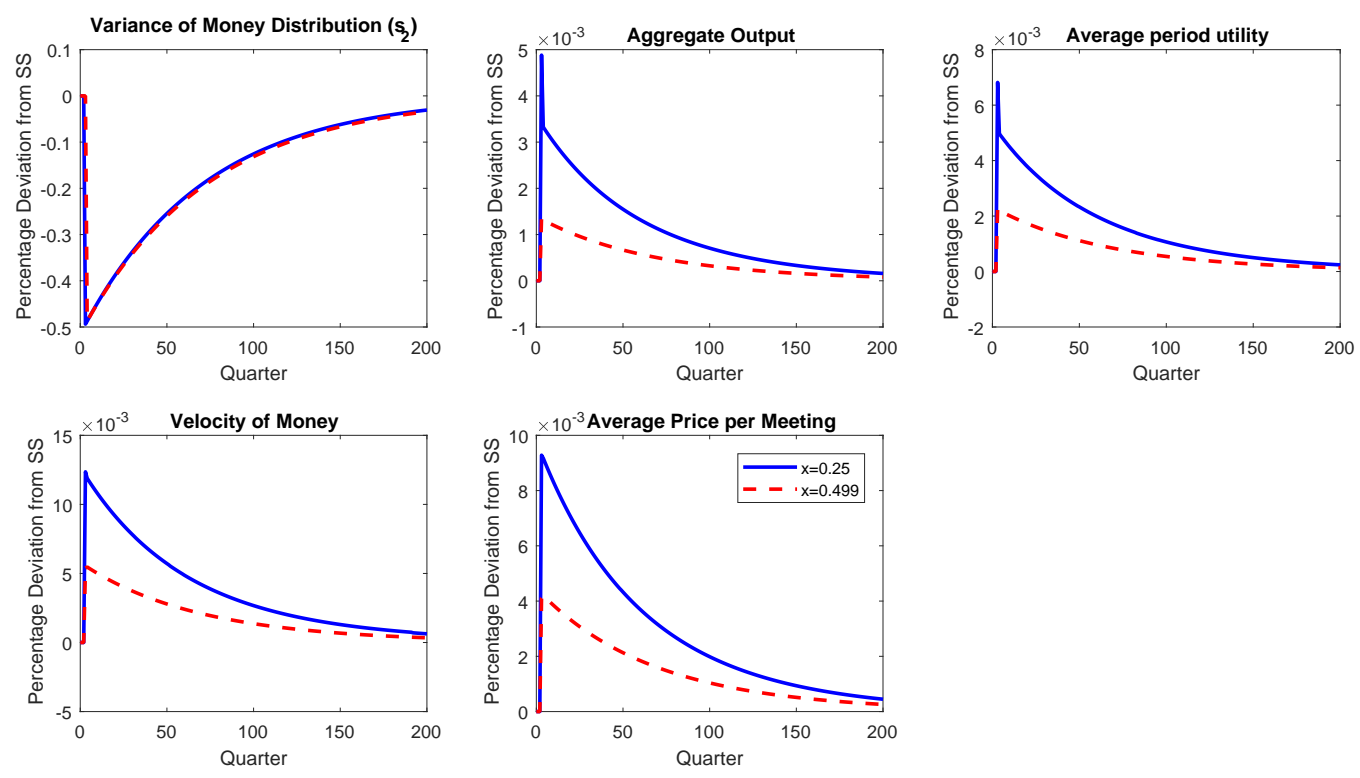

Figure 9: The role of search frictions: Impulse response to positive money growth shock

be easily understood by considering two forces at work. First, the decrease in search frictions allows agents to trade more frequently and contributes to a decline in the persistence of the dispersion of money holdings. Second, the endogenously determined terms of trade also change. Namely, as search frictions decrease (or agents become more patient), they are more willing to wait for "better deals," which implies that on average they will trade smaller fractions of their money holdings and at lower prices (smaller amounts of money change hand for the same quantity). Thus, the velocity of money decreases and as a consequence the distribution evolves at a slower pace. These two forces balance out such that, overall, the persistence of the dispersion of money stays unchanged. Note also that the reduction in velocity and prices leads to a reduction of the dispersion of money holdings in the stochastic steady-state equilibrium, as can be seen in Figure 10. In consequence, fewer agents will be constrained (or be close to being constrained) in their liquidity. This explains why monetary policy shocks have a smaller effect in the economy with less frictions, as seen in Figure 9.

\section{The Effectiveness of Monetary Policy Shocks and Trend Inflation}

Finally, we consider two economies that differ solely in their level of trend inflation, $\bar{\mu}$. We compare our benchmark economy with an economy where money and prices grow on average at $10 \%$ per year, $\bar{\mu}=0.025$. Figure 11 plots the impulse responses to a monetary policy shock of $\varepsilon_{\mu}=0.0025$. 

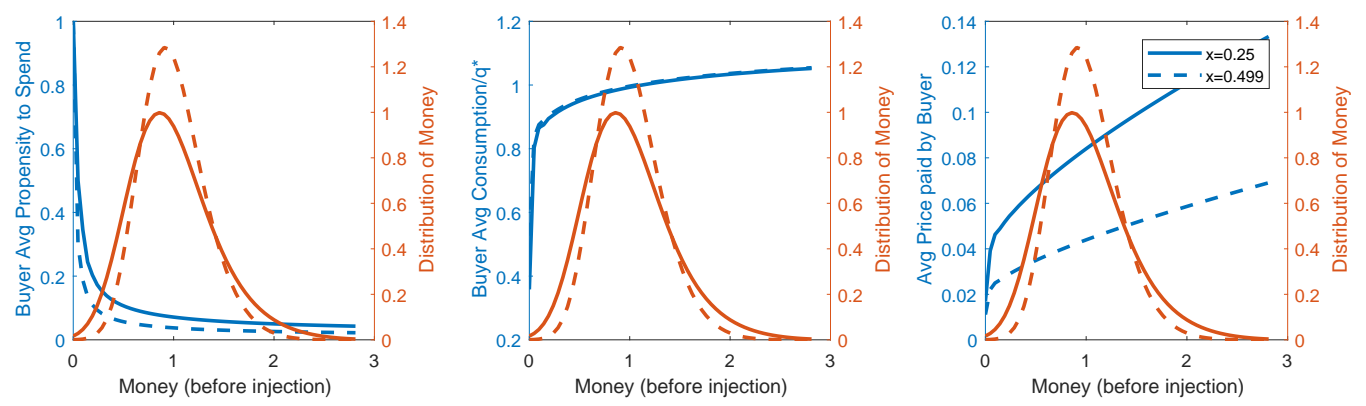

Figure 10: Search frictions: Stochastic steady-state comparison.

First note that the persistence of the dispersion of money holdings is much smaller in the economy with high trend inflation. This is due to the fact that in this economy agents are more willing to spend because money loses value more quickly, as can be seen in Figure 12. This also implies that agents will trade on average at higher prices (as a fraction of $M$ ). This pattern of trade implies that in equilibrium a higher fraction of agents will be constrained in their liquidity - they spend all their money (because they know that their money balances will be replenished as they receive the monetary injection). The higher fraction of agents constrained (or close to being constrained) explains why the redistributive effect of the monetary shock on impact is stronger in the economy with higher trend inflation. However, as discussed, the effect is less persistent, leading to a smaller cumulative effects, as can be seen in Table 4. Also note that, on impact, the asymmetric response of output to positive and negative shocks is stronger with higher inflation. This is consistent with empirical results by Rhee and Rich (1995) and Karras and Stokes (1999a).

Table 4: Effect of Money Growth Shocks at Different Levels of Trend Inflation $(|\varepsilon \mu|=0.25 \%)$

\begin{tabular}{l|r|r|r|r|r|r}
\hline & \multicolumn{2}{|c|}{ SS $\pi=2 \%$} & \multicolumn{2}{c|}{ SS $\pi=10 \%$} & \multicolumn{2}{c}{ Ratio } \\
\hline Variable & On impact & Cumulative & On impact & Cumulative & On impact & Cumulative \\
\hline \% in output & & & & & & \\
Positive shock & 0.00488 & 0.20355 & 0.01197 & 0.09519 & 2.45287 & 0.46765 \\
Negative shock & -0.00551 & -0.20540 & -0.01359 & -0.09600 & 2.46642 & 0.46738 \\
\hline$\% \Delta$ in avg price & & & & & & \\
Positive shock & 0.00928 & 0.56394 & 0.03200 & 0.35553 & 3.44828 & 0.63044 \\
Negative shock & -0.01334 & -0.57859 & -0.03179 & -0.35047 & 2.38306 & 0.60573 \\
\hline
\end{tabular}



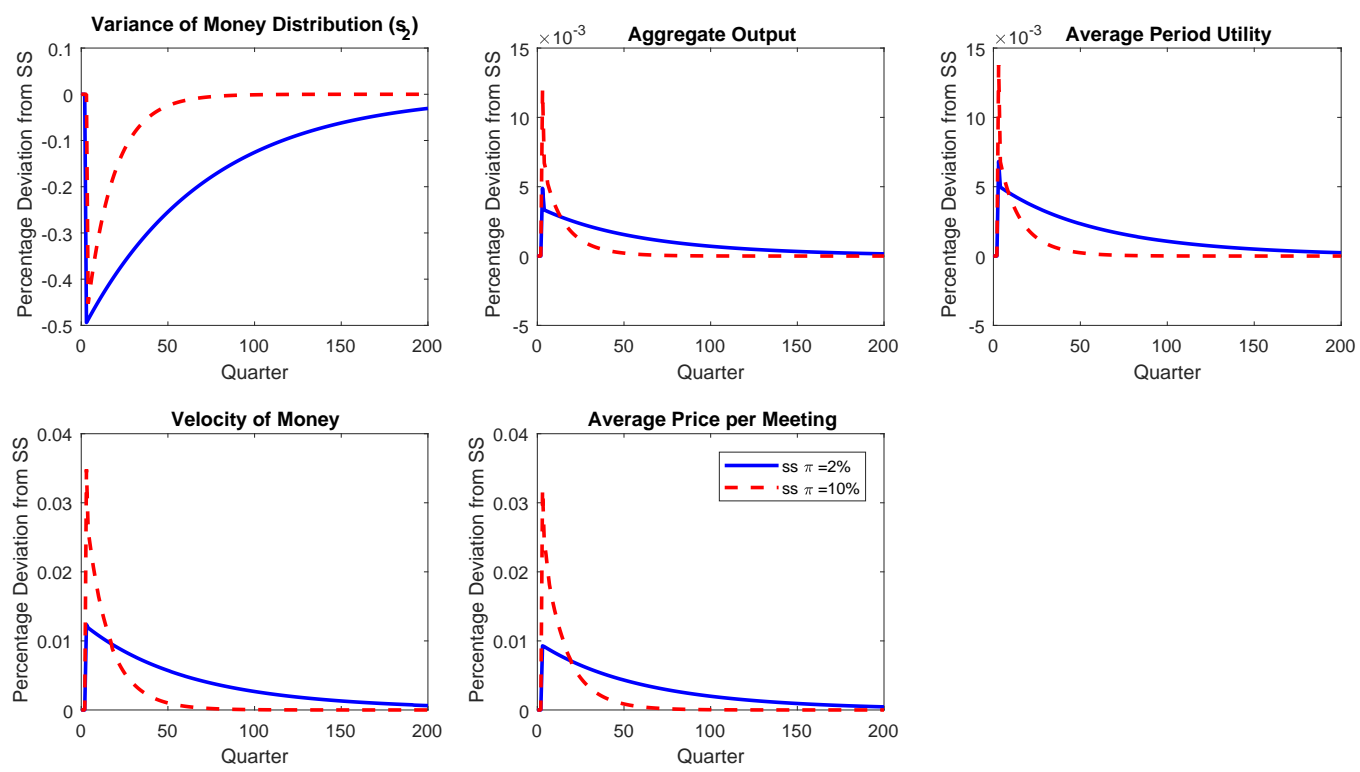

Figure 11: Shock impact as a function of steady-state inflation
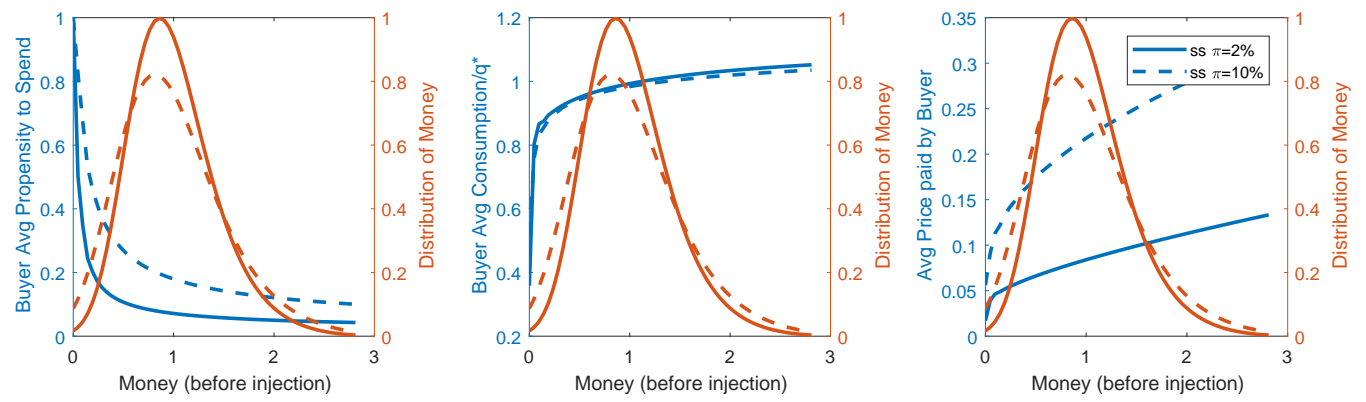

Figure 12: Trend inflation: Stochastic steady-state comparison. 


\section{Robustness: Adding Other Moments}

In this section we analyze the robustness of our analysis to the addition of other moments as state variables. Namely, instead of setting the third moment as a reference moment as in our previous analysis, we expand our state space to include both the second and third moments of the money distribution $\left(s_{2}\right.$ and $\left.s_{3}\right)$. We find that the adding the third moment as a state variable does not significantly affect the equilibrium or the dynamic properties of the economy. The law of motion of the endogenous aggregate states is well approximated by linear functions.

$$
\begin{aligned}
& s_{2}=0.002461-0.334 * \varepsilon_{\mu}+0.987 * s_{2}+0.0002632 * s_{3} \\
& s_{3}=0.0001455-0.141 * \varepsilon_{\mu}+0.005378 * s_{2}+0.979 * s_{3} \quad\left(\text { with } R^{2}=1\right) .
\end{aligned}
$$

Figure 13 compares the impulse responses of the benchmark economy where we only kept track of the second moment of the distribution with the impulse responses when we keep track of the second and third moments as state variables. As can be seen, the impulse responses are mostly unchanged, with just a marginal stronger response of the nominal variables. Note that in our benchmark economy, the third to fifth moments were already used as reference moments, that is, their values were set to their ergodic means and these were used to discipline the shape of the distribution. Our results show that the additional information contained in the third moment beyond its ergodic mean is tiny.

\section{Discussion}

We now briefly discuss how our model and findings are related to different lines of literature. Firstly, our paper belongs to the New-Monetarist research, which studies the effects of monetary policy on decentralized trade in micro-founded monetary models. As discussed before, due to technical difficulties, most of the studies have focused on long-run analysis, and the short-run implications of such models have not been fully explored. The key reason is that the distribution responds endogenously to aggregate shocks and it is technically challenging to keep track of its evolution and to study the complex interaction between ex-post bargaining and the endogenous distribution of money holdings. 

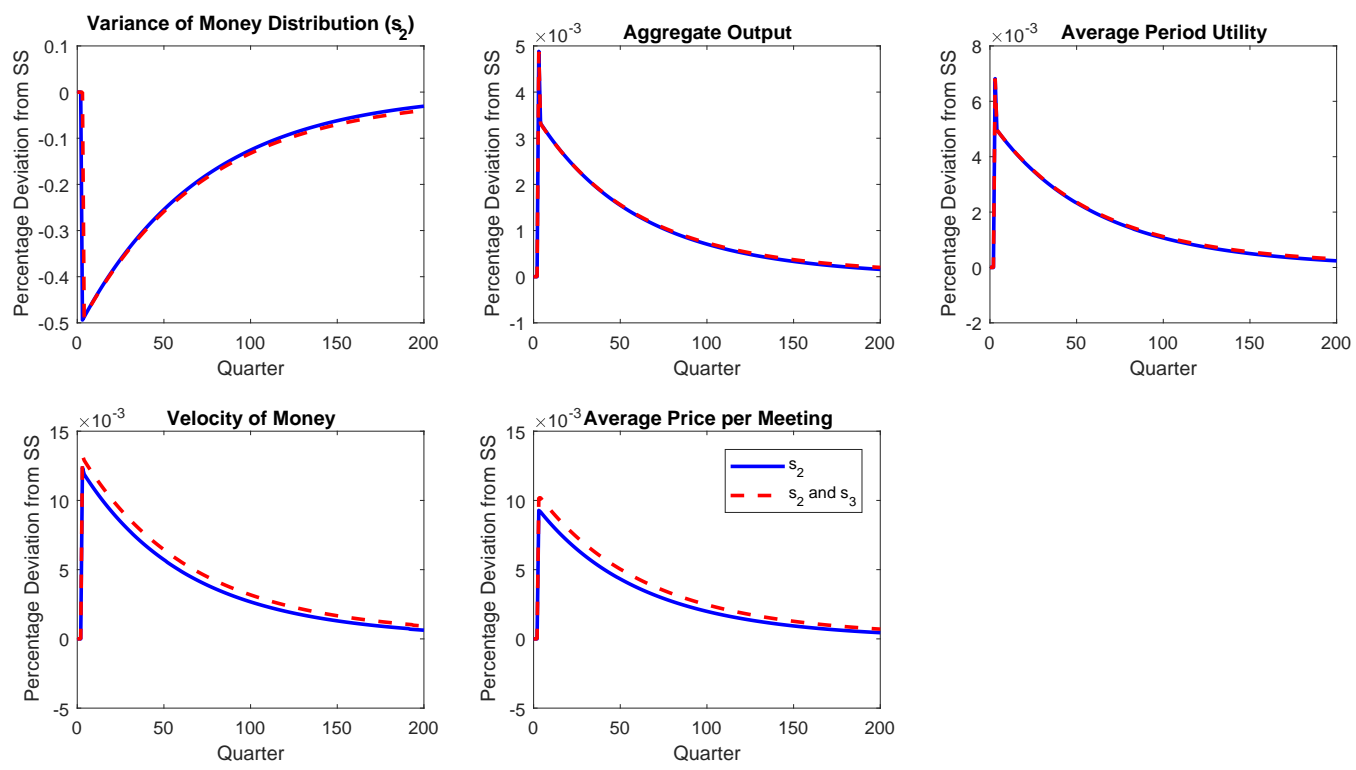

Figure 13: Adding the third moment as a state variable

Only a few existing papers have explored this question. Rocheteau, Weill and Wong (2018) develop a continuous time model with idiosyncratic lumpy consumption opportunities. The direct interaction between the distribution and the terms of trade is avoided by replacing bargaining by competitive prices. In some special cases, they are able to characterize in closed form the transitional dynamics following a one-time money injection. As in our model, a one-time increase in money supply affects the distribution of real balances and consumption levels across households. The reduction in the spread of the distribution leads to an increase in welfare. Rocheteau, Weill and Wong (2019) consider a different environment, where agents have permanent types and trade in alternating decentralized and centralized markets. This setting is analytically more tractable because buyers are not subject to uncertainty regarding their match partners' money holdings and hence their decision does not depend directly on the distribution. They find that a one-time injection of money in a centralized market with flexible prices is not neutral and the effects are non-monotone with the size of the money injection. The money injection generates a redistribution of real balances and consumption. As in our model, buyers who are constrained by their income choose to consume more after receiving the lump-sum transfer. Jin and Zhu (2019) consider an environment similar to ours with expost bargaining and random pairwise matching. The complexity of the computational problem is reduced by assuming money to be imperfectly divisible, introducing 
lotteries and focusing only on one-time shocks. Their paper finds that an expansionary monetary policy can have a positive and persistent effect on output but a negative effect on welfare due to different assumptions regarding preferences and the money transfer scheme.

While our model environment is very different from those in the New-Keynesian literature, our focus on the redistributional effects of monetary policy is related to the recent literature on heterogenous agent new-Keynesian (HANK) models. This literature studies the effects of monetary policy in a cashless economy where agents are subject to uninsurable idiosyncratic risk, nominal rigidities and monopolistic competition. ${ }^{22}$ Our model has a "demand side" similar to those of HANK models in the sense that agents also smooth consumption subject to uninsurable idiosyncratic shocks and a "liquidity" constraint. The "supply side" of our model differs more, as there are no nominal rigidities or monopolistic competition. Instead of trading in a competitive market, agents in our model are subject to decentralized trades, which implies that buyers need to face uncertainty regarding the match-specific terms of trades. Finally, in our model, monetary policy is conducted through changes in the money- growth rate rather than implemented via Taylor rules. Nevertheless, some model implications are similar. For example, our result that poor buyers tend to respond more strongly to monetary shocks is similar to the responses of hand-to-mouth households to a monetary policy shock in Kaplan, Moll and Violante (2018). In addition, our finding of asymmetric responses to monetary shocks is also related to Auclert (2019), who shows that an asymmetry emerges when agents have different marginal propensities to consume depending on how liquidity-constrained they are.

\section{Concluding Remarks}

This paper studied the internal propagation mechanism of a micro-founded search model of money and found that monetary policy can have persistent effects on output, prices and welfare, even in the absence of ad-hoc nominal rigidities. The effects of monetary policy are typically non-linear and asymmetric. Contractionary shocks have bigger effects than expansionary shocks, while bigger shocks are disproportionately more effective. These effects depend not only on policy, but also on trading frictions. For example, the persistence of these effects is governed by search frictions that

\footnotetext{
${ }^{22}$ See Kaplan and Violante (2018) for a survey of the literature.
} 
determine both the exogenous frequency of trades and the endogenous spending patterns of agents. Overall, our result highlights the fact that explicitly modeling the micro-foundation of money is important not only for long-run steady-state analysis, but also for understanding the short-run effects of monetary policy.

In this environment, money is the only asset, and agents will tend to hold excess precautionary balances, making it difficult to match the observed velocity of money (Molico, 2006). In reality, there exist other insurance mechanisms that could reduce agents' incentives to hold precautionary balances. For example, one natural extension is to introduce a progressive tax-transfer scheme or consider non-lump-sum monetary policies.

Adding other assets (e.g., financial assets, physical capital) also provides such insurance role. The introduction of these assets avoids the excessive holding of money balances, potentially allowing the model to match the empirical money demand. Whether explicitly modeling these assets can have other effects on the welfare costs of inflation is an open question. We leave this extension for future research. 


\section{References}

[1] Algan, Yann, Oliver Allais, and Wouter Den Hann. (2008). "Solving heterogeneous-agent models with parameterized cross-sectional distributions." Journal of Economic Dynamics and Control, 32(3), March, 875-908.

[2] Auclert, A. (2019). "Monetary policy and the redistribution channel." American Economic Review, 109(6), 2333-2367.

[3] Berentsen, Aleksander, Gabriele Camera, and Christopher Waller. (2005). "The distribution of money balances and the nonneutrality of money." International Economic Review, 46, 465-487.

[4] Boel, Paola and Gabriele Camera. (2009). "Financial sophistication and the distribution of the welfare cost of inflation." Journal of Monetary Economics, 56(7), October, 968-978.

[5] Boppart, Timo, Per Krusell, and Kurt Mitman. (2018). "Exploiting MIT shocks in heterogeneous-agent economies: the impulse response as a numerical derivative." Journal of Economic Dynamics and Control, 89, 68-92.

[6] Chiu, Jonathan and Miguel Molico. (2010). "Liquidity, redistribution, and the welfare cost of inflation." Journal of Monetary Economics, 57(4), 428-438.

[7] Chiu, Jonathan and Miguel Molico. (2011). "Uncertainty, inflation, and welfare." Journal of Money, Credit, and Banking, 43, October, 487-512.

[8] Coeurdacier, Nicolas, Hélène Rey, and Pablo Winant. (2011). "The risky steady state." American Economic Review, 101(3), 398-401.

[9] Cover, J. P. (1992). "Asymmetric effects of positive and negative money-supply shocks." The Quarterly Journal of Economics 107(4), 1261-1282. doi:10.2307/2118388.

[10] DeLong, J. B. and L. H. Summers. (1988). "How does macroeconomic policy affect output?" Brooking Papers on Economic Activity, 1988(2), 433-494. doi:10.2307/2534535.

[11] Den Hann, Wouter J. (1997). "Solving dynamic models with aggregate shocks and heterogeneous agents." Macroeconomic Dynamics, 1, 355-386. 
[12] Deviatov, Alexei and Neil Wallace. (2001). "Another example in which lump-sum money creation is beneficial." Advances in Macroeconomics, 1, Article 1.

[13] Dressler, Scott. (2011). "Money holdings, inflation, and welfare in a competitive market." International Economic Review, Department of Economics, 52(2), 407-423.

[14] Dressler, Scott. (2016). "A long-run, short-run and politico-economic analysis of the welfare costs of inflation." Journal of Macroeconomics, 47, Part B, March, 255-269.

[15] Jin, Gu, and Tao Zhu. (2019). "Nonneutrality of money in dispersion: Hume revisited."International Economic Review, 60(3), 1329-1353.

[16] Kam, Timothy and Junsang Lee. (2018). "Inflationary redistribution vs. trading opportunities: costs of inflation and financial innovation." Manuscript.

[17] Kaplan, Greg, Benjamin Moll, and Giovanni L. Violante. (2018). "Monetary policy according to HANK." American Economic Review, 108(3), 697-743.

[18] Kaplan, Greg, and Giovanni L. Violante. (2018). "Microeconomic heterogeneity and macroeconomic shocks." Journal of Economic Perspectives, 32(3), 167-94.

[19] Kaplan, Greg, and Guido Menzio. (2015). "The morphology of price dispersion." International Economic Review, 56(4), 1165-1206.

[20] Karras, Georgios. (1996). "Are the output effects of monetary policy asymmetric? Evidence from a sample of European countries." Oxford Bulletin of Economic and Statistics, 58(2), 267278.

[21] Karras, Georgios, and Houston H. Stokes. (1999a). "Why are the effects of money-supply shocks asymmetric? Evidence from prices, consumption, and investment." Journal of Macroeconomics, 21(4), 713-727.

[22] Karras, Georgios, and Houston H. Stokes. (1999b). "On the asymmetric effects of money-supply shocks: international evidence from a panel of OECD countries." Applied Economics, 31 (2), $227-235$. 
[23] Kiyotaki, Nobuhiro and Randall Wright. (1989). "On money as a medium of exchange." Journal of Political Economy, 97, 927-954.

[24] Krusell, Per and Anthony Smith. (1998). "Income and wealth heterogeneity in the macroeconomy." Journal of Political Economy, 106, 867-896.

[25] Lagos, Ricardo and Randall Wright. (2005). "A unified framework for monetary theory and policy analysis." Journal of Political Economy, 113(3), 463-484.

[26] Menzio, Guido, Shouyong Shi and Hongfei Sun. (2013). "A monetary theory with nondegenerate distributions." Journal of Economic Theory, 148(6), 2266-2312.

[27] Molico, Miguel. (2006). "The distribution of money and prices in search equilibrium." International Economic Review, 47, 701-722.

[28] Morgan, Donald P. (1993). "Asymmetric effects of monetary policy." Federal Reserve Bank of Kansas City Economic Review, 78, 21-33.

[29] Ravn, Morten. O. and Martín Sola. (1996). "A reconsideration of the empirical evidence on the asymmetric effects of money-supply shocks: positive vs. negative or big vs. small?" SSRN Electronic Journal. doi:10.2139/ssrn.56134.

[30] Reiter, Michael. (2002). "Recursive computation of heterogeneous agent models." Manuscript, Universitat Pompeu Fabra.

[31] Rhee, Wooheon and Robert W. Rich. (1995). "Inflation and the asymmetric effects of money on output fluctuations." Journal of Macroeconomics, 17(4), 683-702.

[32] Rios-Rull, J. Victor. (1997). "Computation of equilibria in heterogeneous agent models." Federal Reserve Bank of Minneapolis Staff Report 231.

[33] Rocheteau, Guillaume, Pierre-Olivier Weill, and Tsz-Nga Wong. (2018). "A tractable model of monetary exchange with ex post heterogeneity." Theoretical Economics, 13(3), 1369-1423.

[34] Rocheteau, Guillaume, Pierre-Olivier Weill, and Tsz-Nga Wong. (2019). "A heterogeneous-agent New-Monetarist model with an application to unemployment." Journal of Monetary Economics. 
[35] Shi, Shouyong. (1998). "Search for a monetary propagation mechanism." Journal of Economic Theory, 81, 314-352.

[36] Sun, Hongfei and Chenggang Zhou. (2018). "Monetary and fiscal policies in a heterogeneous agent economy." Canadian Journal of Economics, 51(3), 747-783.

[37] Stokey, Nancy L., Robert E. Lucas, and Edward C. Prescott. (1989). "Recursive methods in economic dynamics." Cambridge, Massachusetts; London, England: Harvard University Press.

[38] Ülke, Volkan and M. Hakan Berument. (2016). "Asymmetric effects of monetary policy on economic performance: empirical evidence from Turkey." Applied Economic Letters, 23(5), 353-360. doi:10.1080/13504851.2015.1073836.

[39] Wallace, Neil. (1997). "Short-run and long-run effects of changes in money in a randommatching model." Journal of Political Economy, 105, 1293-1307.

[40] Weise, Charles L. (1999). "The asymmetric effects of monetary policy: a nonlinear vector autoregression approach." Journal of Money, Credit and Banking, 31(1), 85-108.

[41] Williamson, Stephen D. (2006). "Search, limited participation, and monetary policy." International Economic Review 47, 107-128. 


\section{Appendix A: Proof of Result 1}

The terms of trade $d\left(m_{b}, m_{s} ; \varepsilon_{\mu}, \lambda\right)$ and $q\left(m_{b}, m_{s} ; \varepsilon_{\mu}, \lambda\right)$ solve

$$
\max u(q)+V\left[\frac{m_{b}+\mu-1-d}{\mu}, \varepsilon_{\mu}^{\prime}, \lambda^{\prime}\right]
$$

subject to

$$
\begin{aligned}
E_{\varepsilon_{\mu}^{\prime}}\left\{V\left[\frac{m_{s}+\mu-1+d}{\mu}, \varepsilon_{\mu}^{\prime}, \lambda^{\prime}\right]-V\left[\frac{m_{s}+\mu-1}{\mu} ; \varepsilon_{\mu}^{\prime}, \lambda^{\prime}\right]\right\}-c(q) & =0 \\
m_{b}+\mu-1-d & \geq 0 \\
q & \geq 0 .
\end{aligned}
$$

Denoting $\gamma, \phi$ and $\delta$ as the multipliers, respectively, we can derive the FOCs wrt $q$ and $d$ :

$$
\begin{aligned}
q: & u^{\prime}(q)+\delta=\gamma c^{\prime}(q), \\
d: & \gamma V^{\prime}\left(\frac{m_{s}+\mu-1+d}{\mu}\right)=\mu \phi+V^{\prime}\left(\frac{m_{b}+\mu-1-d}{\mu}\right),
\end{aligned}
$$

where, to simplify notations, we have defined

$$
V^{\prime}\left(\frac{m+\mu-1-d}{\mu}\right) \equiv E_{\varepsilon_{\mu}^{\prime}} \frac{\partial}{\partial m} V\left(\frac{m+\mu-1-d}{\mu}, \varepsilon_{\mu}^{\prime}, \lambda^{\prime}\right)
$$

Clearly, $q=d=0$ when buyers have zero balances, i.e. $m_{b}+\mu-1=0$. For buyers with positive balances (i.e. $m_{b}+\mu-1>0$ ), the FOCs imply that there is no trade (i.e. $q=d=0$ ) only if

$$
\begin{aligned}
\delta & =\gamma c^{\prime}(0)-u^{\prime}(0) \\
& =\frac{V_{b}^{\prime}\left(\frac{m_{b}+\mu-1}{\mu}\right)}{V_{s}^{\prime}\left(\frac{m_{s}+\mu-1}{\mu}\right)} c^{\prime}(0)-u^{\prime}(0)>0 .
\end{aligned}
$$

That is, it happens when the buyer is very poor, the seller is very rich, and/or at $q=0$, the marginal cost is very high relative to the marginal utility. When the above condition fails, buyers trade a 
positive amount with the optimal $q$ and $d$ satisfying the constraints and

$$
\frac{u^{\prime}(q)}{c^{\prime}(q)} V^{\prime}\left(\frac{m_{s}+\mu-1+d}{\mu}\right)=\mu \phi+V^{\prime}\left(\frac{m_{b}+\mu-1-d}{\mu}\right)
$$

Assume that $V$ is a function strictly increasing and strictly concave in $m$. The seller's participation constraint is always binding. That is

$$
c(q)=E_{\varepsilon_{\mu}^{\prime}} V\left[\frac{m_{s}+\mu-1+d}{\mu}, \varepsilon_{\mu}^{\prime}, \lambda^{\prime}\right]-E_{\varepsilon_{\mu}^{\prime}} V\left[\frac{m_{s}+\mu-1}{\mu}, \varepsilon_{\mu}^{\prime}, \lambda^{\prime}\right] .
$$

Depending on whether the buyer's money constraint is binding or not, we have two cases:

- When $\phi>0$, the terms of trade satisfy

$$
\begin{aligned}
d & =m_{b}+\mu-1 \\
c(q) & =E_{\varepsilon_{\mu}^{\prime}} V\left[\frac{m_{s}+\mu-1+d}{\mu}, \varepsilon_{\mu}^{\prime}, \lambda^{\prime}\right]-E_{\varepsilon_{\mu}^{\prime}} V\left[\frac{m_{s}+\mu-1}{\mu}, \varepsilon_{\mu}^{\prime}, \lambda^{\prime}\right] .
\end{aligned}
$$

- When $\phi=0$, the terms of trade satisfy

$$
\begin{aligned}
\frac{u^{\prime}(q)}{c^{\prime}(q)} V^{\prime}\left(\frac{m_{s}+\mu-1+d}{\mu}\right) & =V^{\prime}\left(\frac{m_{b}+\mu-1-d}{\mu}\right) \\
E_{\varepsilon_{\mu}^{\prime}} V\left[\frac{m_{s}+\mu-1+d}{\mu}, \varepsilon_{\mu}^{\prime}, \lambda^{\prime}\right]-E_{\varepsilon_{\mu}^{\prime}} V\left[\frac{m_{s}+\mu-1}{\mu}, \varepsilon_{\mu}^{\prime}, \lambda^{\prime}\right] & =c(q) .
\end{aligned}
$$

with $d<m_{b}+\mu-1$.

\section{Binding Money Constraint}

First, we derive the effects of $m_{b}$ on $q$. Since $d=m_{b}+\mu-1$, we have

$$
\begin{aligned}
\frac{d q}{d m_{b}} & =\frac{1}{\mu} \frac{V_{s}^{\prime}}{c^{\prime}(q)}>0 \\
\frac{d^{2} q}{d m_{b}^{2}} & \propto \frac{V_{s}^{\prime \prime} c^{\prime}(q)}{\mu}-V_{s}^{\prime} c^{\prime \prime}(q) \frac{d q}{d m_{b}}<0,
\end{aligned}
$$


where $V_{s}^{\prime} \equiv V^{\prime}\left(\frac{m_{s}+\mu-1+d}{\mu}\right)$ and $V_{s}^{\prime \prime} \equiv V^{\prime \prime}\left(\frac{m_{s}+\mu-1+d}{\mu}\right)$. Second, the effect of $m_{s}$ on $q$ is given by

$$
\frac{d q}{d m_{s}}=\frac{1}{\mu c^{\prime}(q)}\left[V^{\prime}\left(\frac{m_{s}+\mu-1+d}{\mu}\right)-V^{\prime}\left(\frac{m_{s}+\mu-1}{\mu}\right)\right]<0
$$

We are unable to generally sign the second derivative of $q$ with respect to $m_{s}$ as it depends on high order derivatives. It is easy to see that

$$
\begin{aligned}
\frac{d d}{d m_{b}} & =1 \\
\frac{d d}{d m_{s}} & =0 .
\end{aligned}
$$

The F.O.C. implies that the money constraint binds when

$$
\mu \phi=V^{\prime}\left(\frac{m_{s}+m_{b}+2(\mu-1)}{\mu}\right) \frac{u^{\prime}(q)}{c^{\prime}(q)}-V^{\prime}(0)>0
$$

The first term on the RHS is the marginal value of spending the last dollar on current consumption, and the second term is the marginal value of saving a dollar for tomorrow. The first term consists of two parts. The first part, $V^{\prime}$, captures the seller's marginal valuation of money. The second part, $u^{\prime} / c^{\prime}$, captures the effectiveness of transforming seller's disutility of production to buyer's utility of consumption through trade.

\section{Non-binding Money Constraint}

To find the effect of $m_{b}$ on $q$, we totally differentiate conditions (8) and (9) to obtain

$$
\begin{aligned}
u^{\prime \prime}(q) V_{s}^{\prime} d q+\frac{u^{\prime}(q)}{\mu} V_{s}^{\prime \prime} d d & =c^{\prime \prime}(q) V_{b}^{\prime} d q-\frac{c^{\prime}(q)}{\mu} V_{b}^{\prime \prime} d d+\frac{c^{\prime}(q)}{\mu} V_{b}^{\prime \prime} d m_{b} \\
c^{\prime}(q) d q & =\frac{1}{\mu} V_{s}^{\prime} d d
\end{aligned}
$$

where $V_{b}^{\prime} \equiv V^{\prime}\left(\frac{m_{b}+\mu-1-d}{\mu}\right)$ and $V_{b}^{\prime \prime} \equiv V^{\prime \prime}\left(\frac{m_{b}+\mu-1-d}{\mu}\right)$. Combining the two equations, we get

$$
\frac{d q}{d m_{b}}=\frac{c^{\prime}(q) V_{b}^{\prime \prime}}{\mu\left(\left[u^{\prime \prime}(q) V_{s}^{\prime}-c^{\prime \prime}(q) V_{b}^{\prime}\right]+\left[\frac{u^{\prime}(q)}{\mu} V_{s}^{\prime \prime}+\frac{c^{\prime}(q)}{\mu} V_{b}^{\prime \prime}\right] \mu \frac{c^{\prime}(q)}{V_{s}^{\prime}}\right)}>0
$$


and

$$
\frac{d d}{d m_{b}}=\frac{c^{\prime}(q) V_{b}^{\prime \prime}}{\frac{V_{s}^{\prime}}{c^{\prime}(q)}\left[u^{\prime \prime}(q) V_{s}^{\prime}-c^{\prime \prime}(q) V_{b}^{\prime}\right]+u^{\prime}(q) V_{s}^{\prime \prime}+c^{\prime}(q) V_{b}^{\prime \prime}}>0 .
$$

For $\frac{d d}{d m_{b}}<1$ we need that

$$
c^{\prime}(q) V_{b}^{\prime \prime}>\frac{V_{s}^{\prime}}{c^{\prime}(q)}\left[u^{\prime \prime}(q) V_{s}^{\prime}-c^{\prime \prime}(q) V_{b}^{\prime}\right]+u^{\prime}(q) V_{s}^{\prime \prime}+c^{\prime}(q) V_{b}^{\prime \prime}
$$

or,

$$
\frac{V_{s}^{\prime}}{c^{\prime}(q)}\left[u^{\prime \prime}(q) V_{s}^{\prime}-c^{\prime \prime}(q) V_{b}^{\prime}\right]+u^{\prime}(q) V_{s}^{\prime \prime}<0
$$

which given our assumptions is true. Again, the second derivatives depend on higher order derivatives.

To find the effect of $m_{s}$ on $q$, we can totally differentiate conditions (8) and (9) to obtain

$$
\begin{aligned}
u^{\prime \prime}(q) V_{s}^{\prime} d q+\frac{u^{\prime}(q)}{\mu} V_{s}^{\prime \prime} d d+\frac{u^{\prime}(q)}{\mu} V_{s}^{\prime \prime} d m_{s} & =c^{\prime \prime}(q) V_{b}^{\prime} d q-\frac{c^{\prime}(q)}{\mu} V_{b}^{\prime \prime} d d, \\
c^{\prime}(q) d q & =\frac{1}{\mu} V_{s}^{\prime} d d+\frac{1}{\mu} D V_{s}^{\prime} d m_{s},
\end{aligned}
$$

where $D V_{s}^{\prime}=V_{s}^{\prime}\left(\frac{m_{s}+\mu-1+d}{\mu}\right)-V^{\prime}\left(\frac{m_{s}+\mu-1}{\mu}\right)<0$, or

$$
\begin{aligned}
{\left[u^{\prime \prime}(q) V_{s}^{\prime}-c^{\prime \prime}(q) V_{b}^{\prime}\right] d q+\left[\frac{u^{\prime}(q)}{\mu} V_{s}^{\prime \prime}+\frac{c^{\prime}(q)}{\mu} V_{b}^{\prime \prime}\right] d d } & =-\frac{u^{\prime}(q)}{\mu} V_{s}^{\prime \prime} d m_{s} \\
\mu \frac{c^{\prime}(q)}{V_{s}^{\prime}} d q-\frac{D V_{s}^{\prime}}{V_{s}^{\prime}} d m_{s} & =d d .
\end{aligned}
$$

By combining these two conditions, we obtain

$$
\begin{aligned}
-\frac{u^{\prime}(q)}{\mu} V_{s}^{\prime \prime} d m_{s} & =\left[u^{\prime \prime}(q) V_{s}^{\prime}-c^{\prime \prime}(q) V_{b}^{\prime}\right] d q+\left[\frac{u^{\prime}(q)}{\mu} V_{s}^{\prime \prime}+\frac{c^{\prime}(q)}{\mu} V_{b}^{\prime \prime}\right]\left[\mu \frac{c^{\prime}(q)}{V_{s}^{\prime}} d q-\frac{D V_{s}^{\prime}}{V_{s}^{\prime}} d m_{s}\right] \\
\frac{d q}{d m_{s}} & =\frac{\left[\frac{u^{\prime}(q)}{\mu} V_{s}^{\prime \prime}+\frac{c^{\prime}(q)}{\mu} V_{b}^{\prime \prime}\right] \frac{D V_{s}^{\prime}}{V_{s}^{\prime}}-\frac{u^{\prime}(q)}{\mu} V_{s}^{\prime \prime}}{\left[u^{\prime \prime}(q) V_{s}^{\prime}-c^{\prime \prime}(q) V_{b}^{\prime}\right]+\left[\frac{u^{\prime}(q)}{\mu} V_{s}^{\prime \prime}+\frac{c^{\prime}(q)}{\mu} V_{b}^{\prime \prime}\right] \mu \frac{c^{\prime}(q)}{V_{s}^{\prime}}}<0 .
\end{aligned}
$$

Note also that,

$$
\frac{d d}{d m_{s}}=\mu \frac{c^{\prime}(q)}{V_{s}^{\prime}} \frac{d q}{d m_{s}}-\frac{D V_{s}^{\prime}}{V_{s}^{\prime}}
$$

The first term is negative while the second one is positive, thus the sign is indeterminate. For small 
enough $m_{s}$ the first term tends to be small and the second one large, implying $\frac{d d}{d m_{s}}>0$. For large enough $m_{s}$ the opposite is true, implying $\frac{d d}{d m_{s}}<0$.

While, in general, we cannot prove the concavity of $q$ with respect to $m_{b}$ or convexity with respect to $m_{s}$, we can show that if $\frac{d^{2} d}{d m_{b}^{2}}$ is not too large, $q$ is concave in $m_{b}$. To see this, note that, from the seller's participation constraint we can define an implicit function $q=\hat{q}(d)$ so that

$$
\frac{d q}{d m_{b}}=\hat{q}^{\prime}(d) \frac{d d}{d m_{b}}
$$

with

$$
\hat{q}^{\prime}(d)=\frac{V^{\prime}\left(\frac{m_{s}+\mu-1+d}{\mu}\right)}{c^{\prime}(q)}>0 .
$$

Therefore,

$$
\begin{aligned}
\frac{d^{2} q}{d m_{b}^{2}} & =\frac{d}{d m_{b}}\left[\hat{q}^{\prime}(d) \frac{d d}{d m_{b}}\right] \\
& =\frac{d}{d m_{b}} \hat{q}^{\prime}(d) \frac{d d}{d m_{b}}+\hat{q}^{\prime}(d) \frac{d^{2} d}{d m_{b}^{2}}
\end{aligned}
$$

where

$$
\frac{d}{d m_{b}} \hat{q}^{\prime}(d)=\frac{V_{s}^{\prime \prime} \frac{c^{\prime}(q)}{\mu}-V_{s}^{\prime} c^{\prime \prime}(q) \hat{q}^{\prime}(d)}{\left[c^{\prime}(q)\right]^{2}} \frac{d d}{d m_{b}}<0 .
$$

As a result, $\frac{d^{2} q}{d m_{b}^{2}}<0$ if $\frac{d^{2} d}{d m_{b}^{2}}$ is not too big. In particular, $\frac{d^{2} d}{d m_{b}^{2}}=0$ when the CIA constraint is binding, and hence $q$ is a concave function of $m_{b}$. 


\section{Appendix B: Numerical Algorithm}

\section{Computing the Reference Moments}

In what follows we describe the procedure used to compute the reference moments at a point in the numerical algorithm. For a given guess for the value functions, the law of motion, and the policy function, the idea is to simulate the model to obtain more information regarding the shape of the distribution. The procedure works as follows:

1. Use a random number generator to draw a time series for monetary shocks $\left\{\varepsilon_{\mu t}\right\}_{t=0}^{T}$.

2. In period 1, the procedure starts with a given set of moments. To start the algorithm, we begin with the moments of the stationary equilibrium of a model where the shocks are set to their unconditional mean. We set $\bar{N}=6$, that is we use four additional reference moments. Given the set of moments, we use the procedure described above to compute the coefficients of the polynomial used to approximate the density, $\rho^{1}$.

3. Given the value function, the law of motion and the policy rule, we compute the decision rules $d\left(m_{b}, m_{s} ; \varepsilon_{\mu}, s\right)$ (on a grid of money holdings and use interpolation). Given $d$, the monetary transfers, $P\left(m, \rho^{1}\right)$ and the fraction of agents that are buyers and sellers, we can then compute the new moments of the distribution using quadrature. Note that in this step we are using the fact that there is a continuum of agents and computing the moments without sampling variation.

4. Given these new moments, we use again the procedure to compute the coefficients of the density $\rho^{2}$.

5. Repeat the process for the next period until $t=T$.

To ensure that the sample used to obtain information about the cross-sectional distribution has reached (or is at least close to) its ergodic distribution, one should disregard an initial set of observations. We set $T=500$ and discard 200 observation. Given that using this procedure to compute the reference moments is computationally costly we only update the reference moments every 10 iterations of the algorithm, which we describe in more detail in the next section. 


\section{The Algorithm}

The basic strategy of the algorithm is to iterate on the mapping defined by equation (7) starting from an initial guess for $V\left(m, \varepsilon_{\mu}, s_{2}\right)$ and for the law of motion $\Gamma_{n}$. The algorithm works as follows:

- Compute Reference Moments: In iteration 1, we begin by computing the set of reference moments using the procedure described in the last section. As mentioned before, we only update the reference moments every 10 iterations given that the procedure is computationally time-costly.

- Computing the Cross-sectional Distributions: For each state $s_{2}$ on the grid and the associated reference moments previously obtained, we compute the coefficients of the associated densities $P(m, \rho)$.

- Updating the Value Function: Given $V\left(m, \varepsilon_{\mu}, s_{2}\right)$, the law of motion $\Gamma_{n}$ and the densities $P(m, \rho)$ obtained in the last step, for each quintuplet $\left(m, \varepsilon_{\mu}, s_{2}\right)$ we use equation (7) to update the $V$ on the state-space grid using quadrature methods. For the integration, we define $d\left(m_{b}, m_{s} ; \varepsilon_{\mu}, s_{2}\right)$ and $q\left(m_{b}, m_{s} ; \varepsilon_{\mu}, s_{2}\right)$ as functions obtained by solving the bargaining problem when needed. We do not support the decision rules on a grid to avoid introducing approximation errors, which could lead to violations of the participation constraints of the agents, as well as the loss of concavity of the value function.

- Updating the Law of Motion: Given $P(m, \rho)$, the monetary policy rule, and the decision rules $d\left(m_{b}, m_{s} ; \varepsilon_{\mu}, s_{2}\right)$, for each $\left(\varepsilon_{\mu}, s\right)$ on the state space grid, we compute a new set of second moments $s_{2}^{\prime}$. Note that, conditional on the realizations of the aggregate shocks and the current period's cross-sectional distribution, next period's cross sectional distribution is known with certainty. We then use standard projection methods to update the coefficients of $\Gamma_{n}$. Note that this step does not require any kind of simulation procedure and thus avoids introducing cross-sectional sampling variation.

We repeat the steps above until the law of motion has converged. 


\section{Online Appendix: Parametric vs Non-parametric Methods}

In this appendix, we compare the stationary distributions using our parametric method to those obtained based on an non-parametric method. To estimate the stationary distribution non-parametrically, we follow Molico (2006) and use the Gaussian Kernel density estimation method. This method relies on keeping track of a large sample of agents money holdings and simulate meetings and trades. The use of a sample, even if large, introduces sampling error that is absent in the parametric approximation approach.

- Start with an initial guess $\lambda^{0}$ for the probability density function. Given this function, we draw a large sample (size $N=10000$ ) which will be used to keep track of the distribution. ${ }^{23}$

- In each iteration, we update this sample of money holdings by simulating the meeting technology and solving the associated bilateral bargaining problems.

- Using the updated sample, we estimate non-parametrically the new probability density $\lambda^{n+1}$ using the Gaussian kernel density estimation method. Careful choice of the kernel window width is important to avoid oversmoothing (or undersmoothing) of the distribution. After experimentation, a kernel window width of 0.1 times the standard deviation of the sample was chosen.

- The above steps are performed at each iteration until the distribution converges.

Figure 14 compares the stationary distribution using the parametric approximation used in the paper for different money growth rates. Note that the parametric approach yields an approximation that is quantitatively and qualitatively similar to the non-parametric approach.

\footnotetext{
${ }^{23}$ Computational costs limit the size of the sample used, as the approach requires solving the bilateral bargaining problem for each agent in the sample numerous times. For the same reason, using Monte Carlo simulations to address sampling error is too costly.
} 

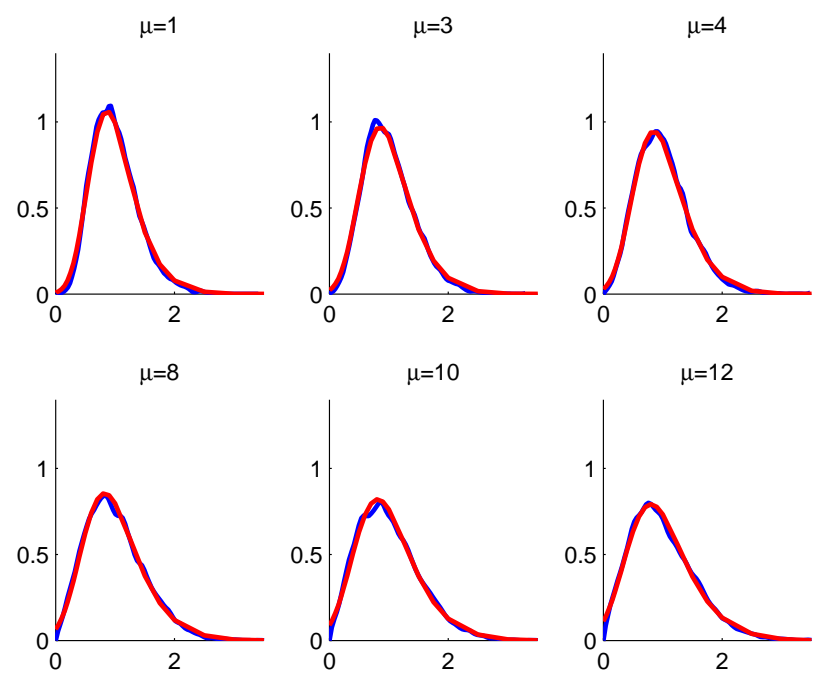

Figure 14: Non-parametric (Blue); Parametric (Red) 